\title{
Spatial and Statistical Analysis of Environmental Stable Isotopes in Precipitates and Groundwaters in Atalanti Coastal Watershed (Central Greece)
}

\author{
Lappas Ioannis ${ }^{1, *}$, Kallioras Andreas ${ }^{2}$ \\ ${ }^{1}$ Division of Surface and Ground Waters, Department of Protection and Management of Water Environment, General Secretariat of Natural Environment \\ and Water, Amaliados 17 Str., Ambelokipi-Athens, Greece. \\ ${ }^{2}$ Laboratory of Engineering Geology and Hydrogeology, School of Mining and Metallurgical Engineering, National Technical University of Athens, Heroon \\ Polytechniou 9 Str., Zografou-Athens, P.C. 15780, Greece.
}

\section{A R T I C L E D E T A I L S}

\section{Article history:}

Received 08 August 2019

Accepted 23 August 2019

Available online 23 September 2019

\section{Keywords:}

$\delta^{18} \mathrm{O}$

$\delta^{2} \mathrm{H}(\delta \mathrm{D})$

Local Meteoric Water Line (LMWL)

D-Excess

Evaporation Process

Isotopic Cross-Sections

Groundwater Recharge

\begin{abstract}
A B S T R A C T
The results of a groundwater-meteoric isotopic research programme held during the period 2014-2017 in the area of Atalanti coastal area, Central Greece are presented in this essay. Thirty-six groundwater samples and twenty-seven rainwater samples from improvised rain collectors were collected during the period 10/2014-04/2015 and 10/2016-05/2017 respectively, analyzed in the laboratory of Isotope Hydrology of the University of Darmstadt in Germany for oxygen isotopes $\delta^{18} \mathrm{O}$ and Deuterium $\left(\delta^{2} \mathrm{H}\right.$ or D). Oxygen and hydrogen stable isotopes were mainly collected in different hydrological conditions (peak precipitation amount in April, drought in October) at increasing distance from the source and at different altitude, from the upper part of the catchment to the lowest part nearby the coastline. These stable isotopes were employed as natural tracers to determine and identify the main recharge areas of the Atalanti drainage basin. Isotopic values $\left(\delta^{18} 0\right.$ and $\left.D\right)$ were then defined in order to identify the groundwater flow path and groundwater residence time inside various geological-lithological formations. From the $\delta^{18} 0$ spatial distribution, the alluvial aquifer seems to be recharging from higher altitudes, through direct infiltration of modern precipitation and possibly laterally from the adjacent geological formations. These potential recharge areas were delineated by combining the isotopic and geological properties of the entire area with the contribution of GIS techniques. The precipitation's isotopic characteristics indicated that wet seasons were relatively depleted compared to dry seasons due to the rainfall amount showing also a significant shift of both the slope and the d-excess (intercept) in the meteoric local water line (LMWL) compared with others such as the world meteoric, Hellenic and Eastern water lines as a result of the enrichment of heavier isotopes probably attributed to evaporation both during the rainfall and surface runoff before infiltration. Elevated d-excess values were observed, probably due to water vapour originating from the Aegean or the mid-eastern Mediterranean. The distance of the station from the shoreline and the altitude were the main factors imprinted in the isotopic signature of precipitation. Inferred groundwater recharge elevations, estimated on the basis of the local vertical isotopic gradient of $\delta^{18} 0$ ranged between 150 and $750 \mathrm{~m}$ a.s.l. Statistics including both linear and multivariate regression analysis was applied to the isotopic data in precipitation and groundwater samples to determine the local meteoric and groundwater water line. The measured stable isotope ratios range from $-9.70 \%$ o to $-5.67 \%$ and $-52.78 \%$ o to $-38.44 \%$ for $\delta 180$ and $\delta \mathrm{D}$, respectively. Isotopic maps and cross-sections were drawn to visualize spatial gradients which reflected the evolution of the water composition at progressive distance from the source. Finally, the secondary processes seemed to be a major factor affecting the initial isotopic signature since they were related to the specific geological and hydrogeological setting including the evaporation of soil and sub-soil water as well as the groundwater recharge is by direct rainfall infiltration with primary evaporation before reaching the groundwater table.
\end{abstract}

\section{Introduction}

Environmental stable isotopes of oxygen and hydrogen (isotope hydrology) as conservative water tracers have been widely applied and established in a large variety of hydrological applications and groundwater resources' assessment as they provide valuable, applicable and supplementary information regarding water management, water origin, groundwater recharge zones (recharge mechanism), hydraulic connections between an aquifer and surface waters, groundwater circulation and flow path modelling, the mechanisms of salinization in coastal aquifers and basin hydrology as well [1]. Isotope studies may lead to a refined understanding of the flow and mixing of the recharge procedures in an area where classic techniques did not provide adequate information about the groundwater's recharge and origin. Also, isotope

*Corresponding Author:i.lappas@prv.ypeka.gr(Lappas Ioannis) hydrology can provide such information because the spatial and temporal variations in the isotopic composition of precipitation are due to isotopic fractionation occurring during the evaporation of seawater and condensation during the advection of water vapour [2, 3]. The most relevant isotopes for hydrological sciences are ${ }^{18} 0$ for oxygen (corresponding to the most abundant isotope ${ }^{16} \mathrm{O}$ ), and ${ }^{2} \mathrm{H}$ (or Deuterium, D) for hydrogen (corresponding to the most abundant isotope ${ }^{1} \mathrm{H}$ ). These isotopes, during evaporation and condensation phases become enriched in one phase and depleted in the other. If the stable isotope content does not change within the aquifer, it reflects the origin of the water, particularly the location, season and processes of recharge. On the other hand, if the isotope content changes along groundwater flow paths, this reflects the history of the water, particularly the mixing and salinization process. Isotopic deviations from the precipitation to the groundwater contnet may indicate a long residence time and a mixing of different water source. For this purpose, the isotopic signatures of groundwater and rainfall are usually used that reflect the discharge and recharge characteristics of the study catchment. 
The objective of the present study was to research the variations in the isotopic parameters of both groundwaters and precipitation occurring in Atalanti catchment to identify the recharge mechanisms, the recharge elevation, the groundwater's residence time, the groundwater-surface water interactions and exchange processes as well within the geological formations. Moreover, the oxygen/hydrogen isotope ratios are temperature dependent indicating the current climatic conditions and thus, evaluating on-going climatic changes. Differential fractionation of $\delta \mathrm{D}$ and $\delta^{18} 0$ occurs as a function of humidity during primary evaporation of water vapor from the ocean and as a function of temperature during secondary evaporation either prior or after the groundwater's infiltration. These two factors affect the slope and intercept of the Local Meteoric Water Line (LMWL) and produce a different LMWL at different locations due to condensation and evaporation processes. Occasionally, a unique terrain environment may create its own special local meteoric water line with a different slope and intercept (so-called d-excess). Greater d-excess than that globally observed, characterizes air masses of continental areas, due to intense evaporation of seawater in conditions of moisture deficit [4-6]. This effect has been widely observed in coastal precipitation in the eastern Mediterranean basin [6, 7]. The slope and intercept of any LMWL, which is the line derived from precipitation collected from local sites, can be significantly different from the global meteoric water line (GMWL). According to Mook [8], in water cycle the values of $\delta^{18} 0$ and $\delta \mathrm{D}$ range between $-450 \% 0<\delta \mathrm{D}<+100 \%$ and $-50 \% 0_{0}<\delta^{18} 0<+50 \%$. The factors affecting the precipitation isotopic composition depend on local conditions such as the temperature, the latitude, the altitude, the continental effect (distance from sea), the seasonal effect, the amount of rainfall and finally, the kinetic effects [9-12].

\section{Experimental Methods}

\subsection{Site Location and Regional Climate Conditions}

The Atalanti watershed lies between 21044'-24039 longitudes and 37045-39029' latitudes in Eastern-Central Greece covering an area and perimeter of $248 \mathrm{~km}^{2}$ and $105 \mathrm{~km}$ respectively (Fig. 1). The drainage basin has flat relief mainly consisted of lowlands with gentle slopes up to $20^{\circ}$ and steeper ones in highlands with slopes reaching $55^{\circ}$ (approximately $3 \%$ ).

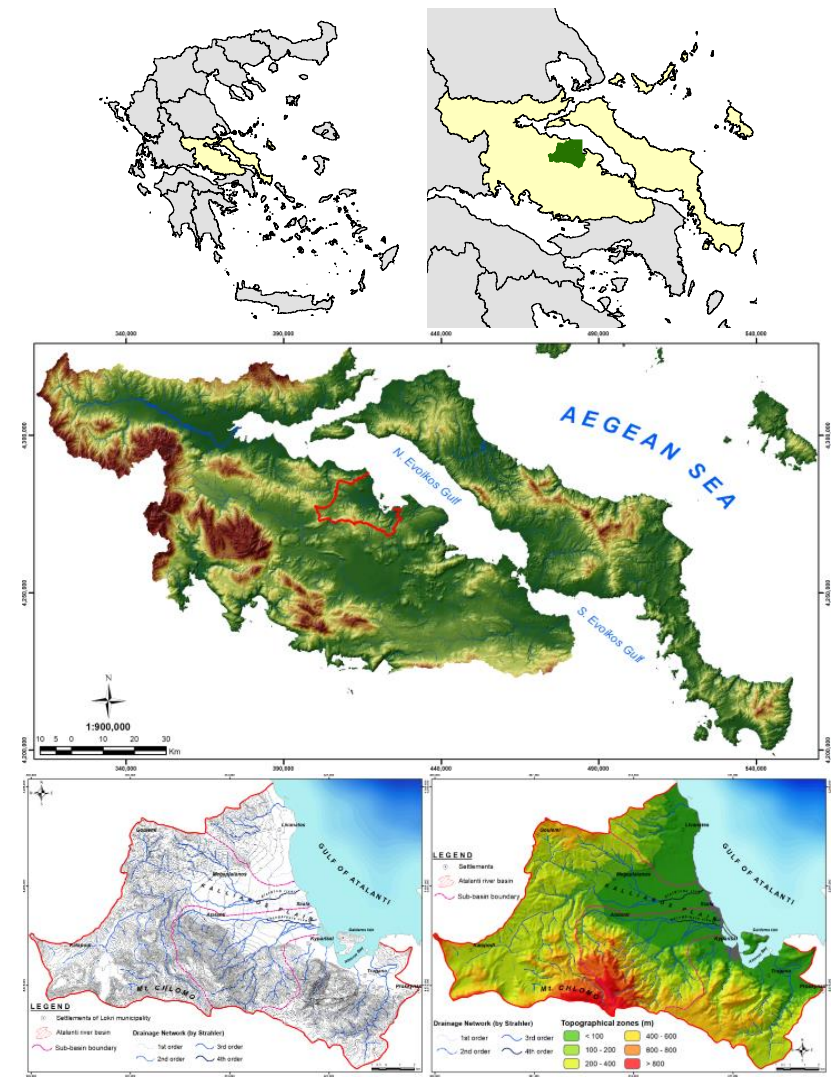

Fig. 1 The study area with its contributing drainage network and topographic zones

The study area is surrounded by hilly and mountainous ranges accounting only for $2.2 \%$ ( $>800 \mathrm{~m}$ ) at the West and South (Mt. Chlomo) and washed by the sea at the East forming a complex geomorphology. The semi-mountainous topographical zone accounts for $4.5 \%(600-800 \mathrm{~m})$ while the flat areas account for $39.5 \%(0-200 \mathrm{~m})$ mostly concerning the https://doi.org/10.30799/jespr.174.19050304 coastal areas. Also, the hilly and semi-hilly areas occupy almost 54\% (200$600 \mathrm{~m}$ ) of the basin. Moreover, the basin's elevation begins from the sea level ending up to $1073 \mathrm{~m}$ above sea level (a.s.l.) crossed by a welldeveloped, partially dense and diverged dendritic drainage network which discharges into Aegean Sea.

At the coastal region the flat and hilly terrain prevails almost covering $76 \%$ of the whole basin area while the mountainous areas occupy only $24 \%$. Also, only temporal streams exist, such as Alargino and Karagkiozis ( $4^{\text {th }}$ order by Strahler) flowing mostly during winter and spring after heavy rainfall events and forming as well $\mathrm{V}$-shape rejuvenated valleys due to intensive tectonic activity. Within the mountainous ranges the first $\left(1^{\text {st }}\right)$ and second $\left(2^{\text {nd }}\right)$ order streams form steep slopes with deep river bed, in particular when carbonate geological formations prevail. Generally speaking, the drainage network within the lowlands is considered as dense due to semi-permeable formations (e.g. clays, silt, fine sand) while in the rocky areas the intensive and active tectonics has formed a significantly sparse drainage. As far as the climate conditions is concerned, the wider area is characterized by mild wet winters and hot, dry summers (typical Mediterranean climate with $\mathrm{C}_{\mathrm{sa}}$ type according to Köppen classification) with the mean annual precipitation and the air temperature equals to $819.1 \mathrm{~mm}$ and $16.8{ }^{\circ} \mathrm{C}$ respectively [13-16]. Almost $75 \%$ of the total rainfall takes place in the wet season from October to April with significantly rainfall non-uniformity between the lowlands and highlands with observed higher values in the mountains and lower ones in the valleys (Kalliaros plain), as expected. The climatic main feature in the region is the rotation period of a wet and cold season starting in October, according to precipitation and air temperatures and a dry and a hot one, starting in May.

\subsection{Geological and Hydrogeological Background}

Geologically speaking, the study area belongs to the Subpelagonian geotectonic zone (internal Hellinides) in a closed basin with post alpine deposits covering the lowlands [17]. The deposits have come from the surrounding mountain range rocks. The Atalanti basin consists of formations which are as follows (Fig. 2): (a) Paleozoic formations (metamorhic-ultrabasic rocks) consisting of shales, schists, sandstones and conglomerates, (b) Triassic and Jurassic dolomites, limestones and ophiolitic rocks (gabbro, diabases, peridotites, serpentines), (c) Creataceous limestones and flysch comprising the bedrock along the eastern, northern and southern outcrops of the alluvial plain, (d) Tertiary (Neogene-Pleiocene) sediments that were deposited after the closed basin formation consisting of marls, calcareous marls, marly limestones, clays, sandy loams, lignite and conglomerates and (e) quaternary formations that have been deposited at the lower parts of the basin with materials derived from weathering of all previous formations, which come across at higher topographic positions such as coastal sandy and clay-sandy sediments, debris cones and loose sediments of silts, sands and pebbles. These sediments constitute the most recent formations covering the lowland part whereas in the coastal zone sand dunes and coastal sediments prevail. The main feature of the geological regime during Miocene is the large-scale faults in Atalanti basin which have created many faulting zones with directions towards West-Northwest and North-Northeast [18-20]. Finally, the Atalanti normal faulting zone of 30 $\mathrm{km}$ length with NW-SE direction has reactivated many other faults giving significant earthquakes of which two of them took place on April 1894 A.D. with magnitudes of 6.4 and 6.9 [21-23].

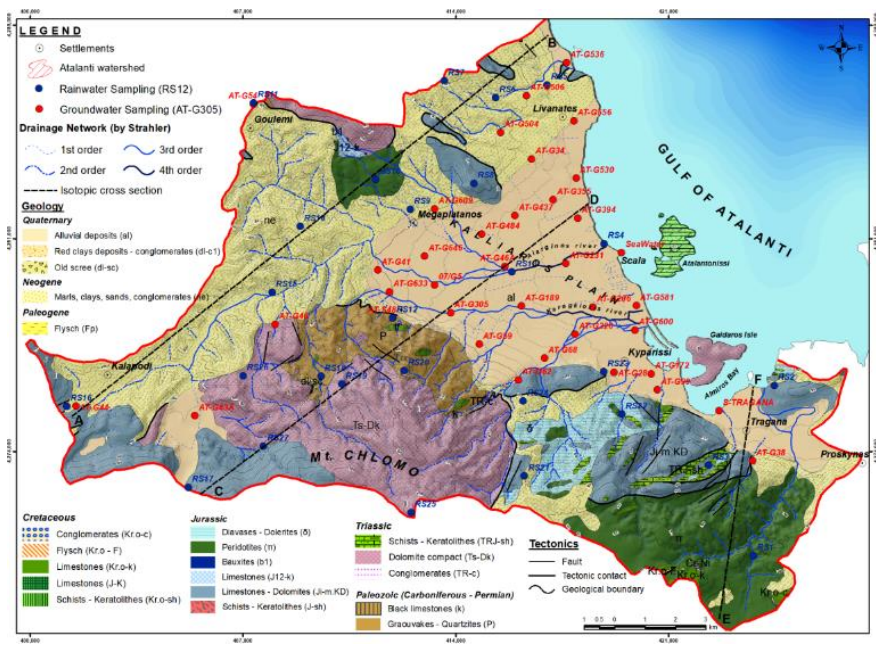

Fig. 2 Geological map of the study area [17]. The black dashed lines represent the isotopic cross-sections. The red and blue dots show the groundwater and rain sampling sites respectively for the isotopic analyses 
The hydrogeological behaviour of the aforementioned geological formations depends on the lithological composition, degree of diagenesis and porosity. Hydrogeologically speaking, the area of interest is consisted of two main groups of rocks in which the groundwater flow mechanism and the storage capacity vary considerably. The first group consists of granular formations in which the hydraulic conductivity is based on the pores between the grains. The second group is composed by hard basement rocks which are limestones and igneous rocks, the hydraulic conductivity of which depends on fractures, fissures, cracks, conduits, karst pipes and other discontinuities that cross their mass (Fig. 3). Permeable and karstic formations favour groundwater infiltration, whereas impermeable ones, such as crystalline rocks, favour surface runoff. The main aquifer is developed in carbonate rocks; on the other hand, aquifers of lower hydrocapacity are developed in the QuaternaryNeogene formations and igneous rocks. It is estimated that there is lateral communication between aquifers in carbonate rocks and the NeogeneQuaternary deposits, forming unconfined and semi-confined aquifers. Unconfined aquifers are developed in carbonate rocks as well in granular formations with large effective porosity. On the other hand, the confined aquifers are developed within Neogene formations. The alluvial deposits due to their heterogeneity may be regarded as unconfined or semiconfined aquifers forming individual aquifers which are, though, practically interconnected and may be considered as a unified heterogeneous alluvial aquifer [13] with piezometric levels ranging from 1.2 to $86 \mathrm{~m}$ (below surface). Finally, ground water flow direction is mainly from West towards East, that is, to the sea (Gulf of Atalanti).

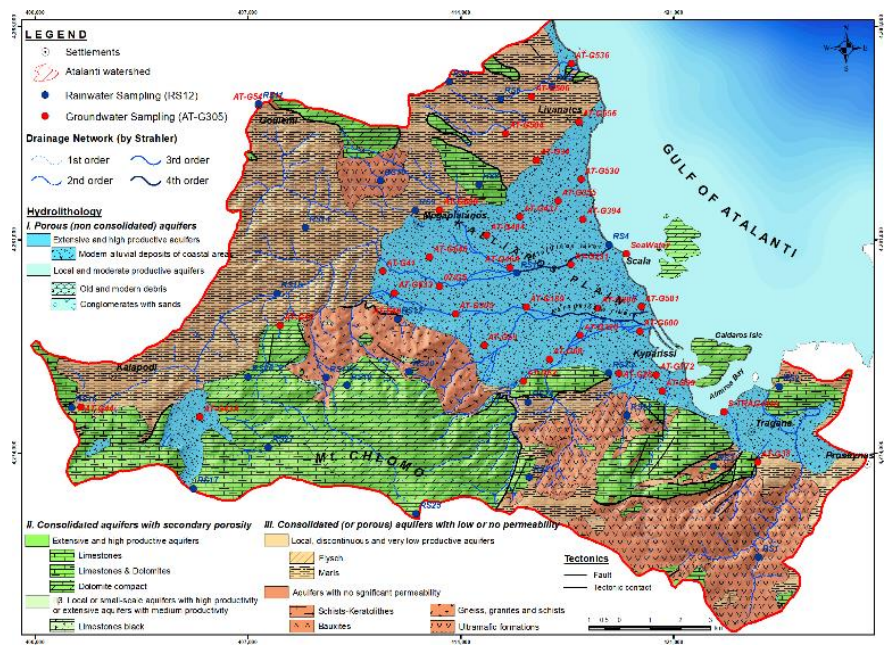

Fig. 3 Hydrolithological map of the study area. The red and blue dots show the groundwater and rain sampling sites respectively for the isotopic analyses

\subsection{Methodology of Analysis}

With isotope hydrology the altitude of the recharge area of an aquifer can be determined, as well as, the mixing between different types of groundwater, the degree of mixing of surface and groundwater, the rate of evaporation, the inflow and outflow of surface water systems, the groundwater salinization and the groundwater residence time in aquifers [24]. As isotopic ratio, $\mathrm{R}$, of an isotope in a water sample, is the ratio of the number of atoms of the isotope in the sample to the total number of atoms of the same element in the sample. All the measurements need to be compared with a reference standard, so the statistical errors being negligible. Consequently, the notation $\delta$ is defined as follows,

$$
\begin{gathered}
\delta(\%)=\frac{\left(R_{x}-R_{\text {st }}\right)}{R_{\text {st }}} \cdot 1000 \\
\delta^{18} O_{\text {sample }}=\left(\frac{\left({ }^{18} \mathrm{O} /{ }^{16} \mathrm{O}\right)_{\text {sample }}}{\left({ }^{18} \mathrm{O} /{ }^{16} \mathrm{O}\right)_{\text {reference }}}-1\right) \cdot 1000, \delta^{2} H_{\text {sample }}=\left(\frac{\left({ }^{2} H / I^{1} H\right)_{\text {sample }}}{\left({ }^{2} H /{ }^{1} H\right)_{\text {reference }}}-1\right) \cdot 1000
\end{gathered}
$$

If the value of $\delta$ is negative $\left(\mathrm{R}_{\mathrm{x}}-\mathrm{R}_{\mathrm{st}}<1\right)$ then the sample is "depleted" in the light ${ }^{16} \mathrm{O}$ isotope (low amount of evaporation and high recharge altitude) while if it is positive $\left(R_{x}-R_{s t}>1\right)$ the sample is "enriched" in comparison to the standard (Fig. 4) which means lower recharge altitude and more exposed to the evaporation effect [25].

Water found in soil and subsoil retains the characteristics of meteoric and surface water infiltrating the ground (unless mixed with other waters of different isotopic origin) so the stable isotopes can be functioned as natural tracers. In the process of oceanic water evaporation becoming inland rainfall, a sequence of isotope fractionations causes variations in the composition of the isotope values of $\mathrm{O}$ and $\mathrm{H}$ in continental meteoric https://doi.org/10.30799/jespr.174.19050304 water. Since the process of fractionation is based on the process of the isotopes' equilibrium of evaporation, there is an equation that domains in the distributions of isotope values of oxygen and hydrogen in precipitation.
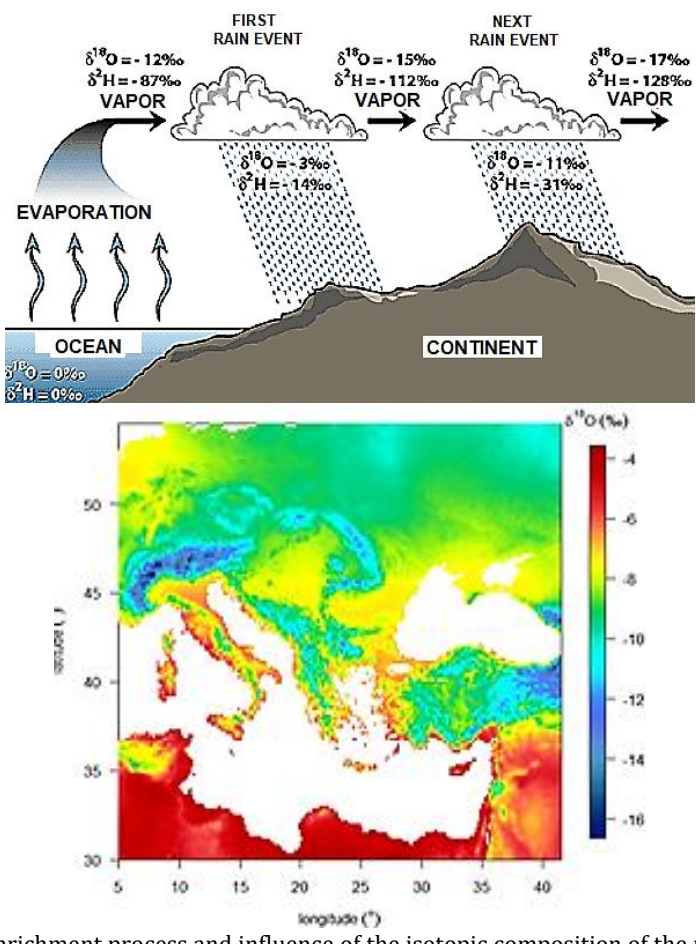

Fig. 4 Enrichment process and influence of the isotopic composition of the meteoric water in $\delta^{18} O$ and $\delta \mathrm{D}$ and spatial distribution of $\delta^{18} \mathrm{O}-\delta \mathrm{D}$ in the Eastern Mediterranean and globally $[10,26]$

The empirical equation found by Craig [27-30] forms a linear regression method to analyze the oxygen and hydrogen isotopes' composition in precipitation, snow and river water around the world, known as the Global Meteoric Water Line (GMWL, Fig. 5),

$$
\delta \mathrm{D}=8 \delta^{18} \mathrm{O}+10(\mathrm{SMOW})
$$

A later study implemented by the International Atomic Energy Agency (IAEA), water samples from rainfall stations only were collected globally forming the following equation [31-35],

$$
\delta \mathrm{D}=(8.13 \pm 0.08) \delta^{18} \mathrm{O}+(10.8 \pm 0.64)(\mathrm{V}-\mathrm{SMOW})
$$

However, some areas having different evaporation and humidity conditions (e.g., air temperature), or a unique terrain relief, create special local meteoric water lines with a different slope and intercept. This intercept is also called deuterium excess or d-excess $\left(d=\delta D-8 \delta^{18} 0\right)$. In tempered climates $d$-excess ranges between $0 \%$ and $+20 \% 0[4,5,33]$ with mean global value of $+10 \%$. However, areas may have different slopes and intercepts due to different rainfall evaporation conditions or source evaporation conditions in various air mass sources [2,3, 36-40]. The isotopes obtain isotopic equilibrium since an isotopic fractionation does not occur. Rainwater which falls in coastal areas obtains, more or less, the same isotopic content as seawater, however, rainwater falling on the continental is generally depleted in both heavy isotopes $\left({ }^{18} \mathrm{O}\right.$ and $\left.{ }^{2} \mathrm{H}\right)$, the difference rate being increasing as the distance from the coastline increases. Generally, the rainwater in high altitude areas becomes more depleted in heavy isotopes than this in lowlands at coastal plains [41, 42].

The stable isotopes of oxygen and hydrogen $\left({ }^{18} \mathrm{O},{ }^{2} \mathrm{H}\right)$ are often used for the water separation with different recharge areas. The coastal meteoric waters seem to have heavier isotopic composition compared with the inland waters. The continental waters area depleted in $\delta \mathrm{D}$ and $\delta^{18} 0$ having negative values. Nevertheless, the Mediterranean seawater which is highly evaporated takes positive $\delta$-values of the above stable isotopes. Deviations to even more positive values (Fig. 5) take place in areas where warmer, dryer and low relative humidity $(<81 \%)$ climates prevail such as in Eastern Mediterranean with the Eastern Mediterranean Water Line (EMWL) being [6],

$$
\delta \mathrm{D}=8 \delta^{18} 0+22 \% 0(\mathrm{~V}-\mathrm{SMOW})
$$

while for the Western Mediterranean is [43],

$$
\delta \mathrm{D}=8 \delta^{18} \mathrm{O}+13.7 \% 0(\mathrm{~V}-\mathrm{SMOW})
$$



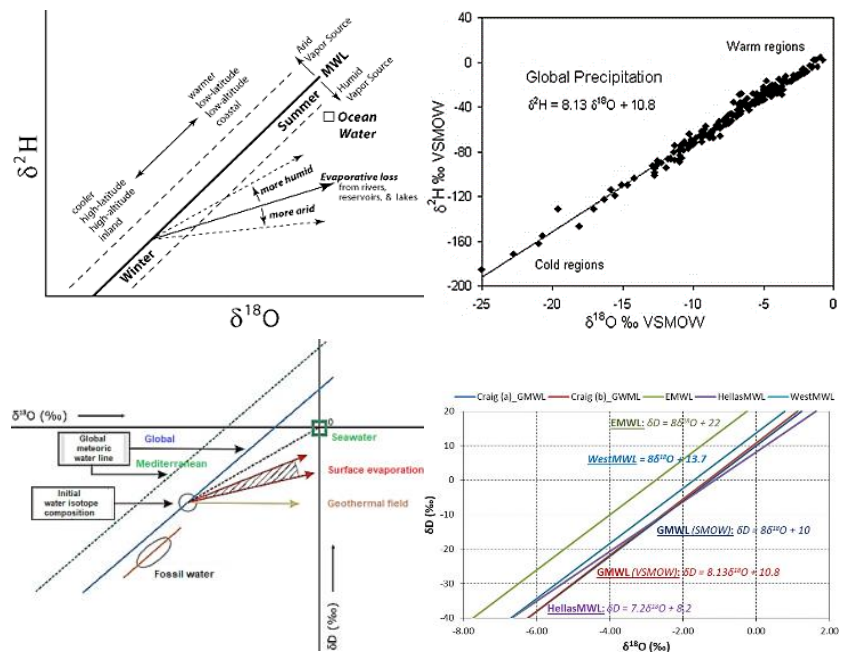

Fig. 5 Initial and modified Global Meteoric Water Line (GMWL), deviations from the meteoric line due to evaporation conditions and local Meteoric Water Lines of the Eastern Mediterranean and Greece $[10,24,44-48]$ with modifications by the authors)

Moreover, the slope a of the general equation $\delta D=\alpha \delta^{18} O+d$ constantly changes from region to region taking values between 4 and 6 for highly evaporated waters, while waters with values close to $8(a \approx 8)$ are proved to have meteoric origin with no or little evaporation process. Furthermore, a Local Mean Water Line (LMWL) can be formed in every area based on the precipitation isotopic measurements which is differentiated from Global Meteoric Water Line (GMWL). As illustrated in Fig. 5, several meteoric water lines are drawn which are diverged from the GMWL such as the Hellenic Meteoric Water Line given by the equation [49-51],

$$
\delta \mathrm{D}=7.2 \delta^{18} \mathrm{O}+9.3 \% \text { (V-SMOW) }
$$

\subsection{Field Work, Sampling Process and Data Acquisition-Preparation}

In order to fully evaluate and clarify the recharging and discharging aquifers' conditions, the groundwater flow regime and in particular the water resources' renewal rate, isotopic sampling $\left(\delta^{18} 0, \delta \mathrm{D}\right)$ was performed from groundwater and meteoric water samples across the Atalanti catchment during both wet and dry periods. Each sampling location was geo-referenced by a portable global positioning system (GPS) to locate the points and to set up future field surveys. Isotopic analyses for both the groundwater and rain samples were conducted at the Isotope Hydrology laboratory of the University of Darmstadt in Germany. The rain water sampling was performed by improvised rain collectors. Specifically, groundwater sampling was carried out in 36 wells and boreholes during two campaigns from Oct-2014 to Apr-2015 covering an altitude from $2 \mathrm{~m}$ to about $500 \mathrm{~m}$, while rain water sampling (single rainfall event) in 27 rain collectors was established during four campaigns between Oct-2016 and May-2017 on rainy days per $100 \mathrm{~m}$ elevation distance at different altitudes ranging from about $0 \mathrm{~m}$ to approximately $750 \mathrm{~m}$ a.s.l. (Fig. 6). Samples were collected in October to represent late summer and early fall precipitation, in January to represent mid-winter rainfall, in March to represent peak precipitation amount and in May to represent late spring and early summer precipitation.

Rain water was collected to establish the local meteoric water line (LMWL), which represents the isotopic signature of local rain, one of the most important input sources of the groundwater. Precautions were taken to avoid any evaporation of rain water during the retention time in the collector.

Available hydro-meteorological datasets from the official meteorological and hydrological stations were obtained from the Hellenic National Meteorological Service and the Ministry of Environment and Energy of Greece (Fig. 7). All the sampling sites were allocated and spatially distributed across the Atalanti watershed, as presented in Fig. 8, so as to obtain the isotopic character of the whole basin.
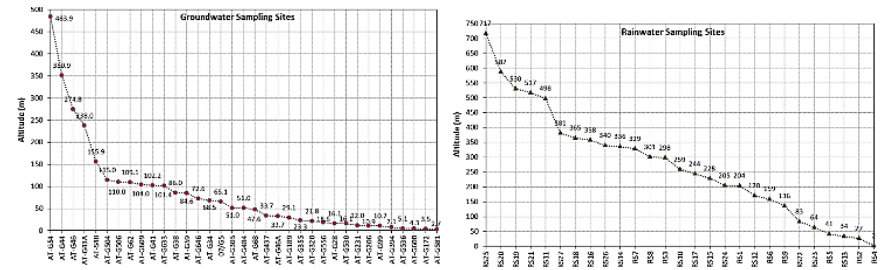

Fig. 6 The sampling sites' altitude ( $m$ a.s.l.) both for groundwater and rainwater (in descending order)

https://doi.org/10.30799/jespr.174.19050304

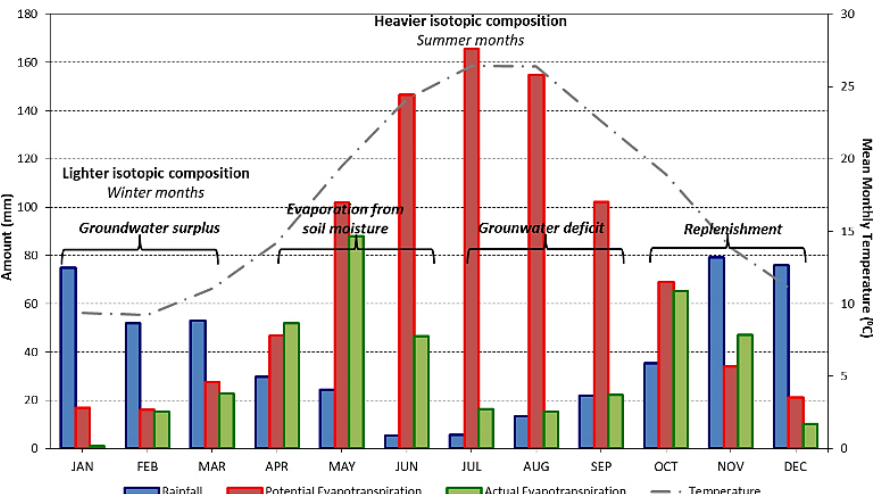

Fig. 7 The seasonal variation of the atmospheric parameters of the Atalanti river basin

For the $\delta^{18} 0$ and $\delta D$ measurements, the samples were collected in 50 $\mathrm{mL}$ polyethylene (HDPE) bottles directly from the source which were first rinsed in sample water several times and then filtered through cellulose filters $(0.45 \mu \mathrm{m})$, filled to the top avoiding air bubbles inside and double tightly capped to minimise the air entrapment as well as to avoid the evaporation process and post-sampling fractionation. Once the samples were taken, they were stored in a portable fridge until they were transported to the laboratory for the analyses. The groundwater samples were taken after removing several well water volumes, using pumps already installed in these wells.
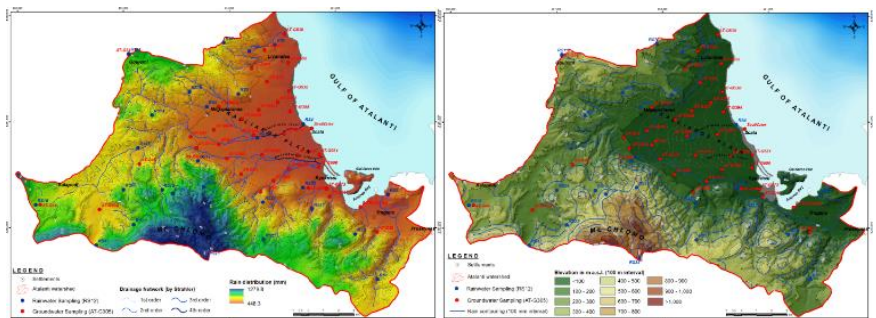

Fig. 8 The rain distribution raster (left) and contour (right) map of the Atalanti river basin

This was done to remove the aquifer's stagnant water acquiring fresh water samples for analysis. Also, sampling procedure for precipitation was in accordance with IAEA guidelines. In particular, the stable isotope ratio of oxygen $\left({ }^{18} \mathrm{O} /{ }^{16} \mathrm{O}\right)$ was determined by conventional mass spectrometry (Isotope Ratio Mass Spectrometry - IRMS) with the measurement accuracy and precision of $\pm 0.21 \%$ for the value of $\delta^{18} 0$ and $\pm 0.53 \%$ for the value of $\delta \mathrm{D}$.

Stable oxygen isotopic compositions were analyzed using the $\mathrm{CO}_{2}-\mathrm{H}_{2} \mathrm{O}$ equilibration technique [36] and hydrogen isotope analyses were performed using the zinc reduction method at $450{ }^{\circ} \mathrm{C}$ [40]. The measurements were reported (Tables 1 and 2), hereafter, in delta $(\delta)$ notation as per million (\%o) with respect to the international Vienna Standard Mean Ocean Water (V-SMOW) and also, geostatistical modelling was carried out so as to visualize the spatial variation of the obtained isotopic data.

Finally, it has to be pointed out that resampling has to be conducted to further refine the expected seasonal variation of the isotopic ratios across the study area.

\section{Results and Discussion}

\subsection{Data Regression Analysis}

The study of atmospheric precipitations as regards their isotopic composition (stable isotopes of $\delta^{18} O$ and $\delta D$ ) was based on data from wells, boreholes and rainfall sites within the Atalanti catchment. Rainfall collectors related to the study area, did not significantly differ in latitude, thus the differences in the isotopic content attributed to this parameter were negligible. Oreography, in particular the altitude, as well as seasonality, have a significant effect on the isotopic composition of rainfalls and it has been proved that the value of $\delta^{18} \mathrm{O}$ decreases as altitude increases, while a gradient of $\delta^{18} \mathrm{O}$ of $-0.437 \%$ o/ $100 \mathrm{~mm}$ is estimated. The $\delta^{18} \mathrm{O}$ ranges from $-9.70 \% \mathrm{~V}$-SMOW, at an altitude of $720 \mathrm{~m}$, while at sea level $(\sim 2 \mathrm{~m})$ it is $-5.67 \%$ V-SMOW, while $\delta \mathrm{D}$ ranges from $-52.78 \%$ o to $38.44 \%$ V-SMOW. The impact of the distance from the sea to the precipitation's isotopic content was considered to be small due to the relatively small distances from the coastline (Fig. 9). 
Table $1 \delta^{18} \mathrm{O}, \delta \mathrm{D}$ and d-excess values for groundwater sampling sites

\begin{tabular}{|c|c|c|c|c|c|c|c|c|c|c|c|c|c|c|c|c|}
\hline \multirow{2}{*}{$\frac{\mathrm{ID}}{07 / \mathrm{G} 5}$} & \multirow{2}{*}{$\begin{array}{l}\text { Sampling Date } \\
18 / 10 / 2014\end{array}$} & \multicolumn{3}{|c|}{$\delta^{18} 0(\% 0)$} & \multicolumn{3}{|c|}{$\delta \mathrm{D}(\% 0)$} & \multirow{2}{*}{$\begin{array}{l}\text { d-excess (\%) } \\
12.32\end{array}$} & \multirow{2}{*}{$\begin{array}{l}\text { Sampling Date } \\
22 / 4 / 2015\end{array}$} & \multicolumn{3}{|c|}{$\delta^{180}(\% 0)$} & \multicolumn{3}{|c|}{$\delta \mathrm{D}(\%)$} & \multirow{2}{*}{$\begin{array}{l}\text { d-excess (\%o) } \\
15.45\end{array}$} \\
\hline & & -6.23 & \pm & 0.05 & -38.81 & \pm & 0.25 & & & -6.98 & \pm & 0.25 & -41.01 & \pm & 0.20 & \\
\hline AT-G172 & $18 / 10 / 2014$ & -7.20 & \pm & 0.01 & -41.36 & \pm & 0.04 & 10.76 & $22 / 4 / 2015$ & -6.14 & \pm & 0.29 & -35.95 & \pm & 0.39 & 13.48 \\
\hline AT-G189 & $18 / 10 / 2014$ & -7.05 & \pm & 0.07 & -41.23 & \pm & 0.48 & 11.25 & $22 / 4 / 2015$ & -7.60 & \pm & 0.04 & -40.57 & \pm & 0.34 & 12.76 \\
\hline AT-G206 & $18 / 10 / 2014$ & -7.25 & \pm & 0.02 & -42.30 & \pm & 0.15 & 11.48 & $22 / 4 / 2015$ & -6.47 & \pm & 0.04 & -38.88 & \pm & 0.36 & 15.18 \\
\hline AT-G231 & $18 / 10 / 2014$ & -7.03 & \pm & 0.13 & -40.89 & \pm & 0.53 & 11.03 & $22 / 4 / 2015$ & -7.41 & \pm & 0.29 & -40.06 & \pm & 0.16 & 12.92 \\
\hline AT-G28 & $18 / 10 / 2014$ & -7.34 & \pm & 0.01 & -41.65 & \pm & 0.05 & 10.47 & $22 / 4 / 2015$ & -7.58 & \pm & 0.54 & -42.92 & \pm & 3.11 & 15.19 \\
\hline AT-G305 & $18 / 10 / 2014$ & -7.33 & \pm & 0.01 & -42.37 & \pm & 0.05 & 11.21 & $23 / 4 / 2015$ & -8.07 & \pm & 0.11 & -41.72 & \pm & 0.15 & 12.19 \\
\hline AT-G320 & $18 / 10 / 2014$ & -7.21 & \pm & 0.08 & -41.85 & \pm & 0.32 & 11.22 & $23 / 4 / 2015$ & -6.73 & & 0.37 & -39.23 & & 0.17 & 14.60 \\
\hline AT-G34 & $18 / 10 / 2014$ & -7.10 & \pm & 0.01 & -42.14 & \pm & 0.01 & 11.98 & $22 / 4 / 2015$ & - & \pm & - & - & \pm & - & - \\
\hline AT-G355 & $18 / 10 / 2014$ & -8.31 & \pm & 0.04 & -46.75 & \pm & 0.05 & 11.45 & $23 / 4 / 2015$ & -6.38 & \pm & 0.04 & -38.00 & \pm & 0.25 & 14.63 \\
\hline AT-G38 & $18 / 10 / 2014$ & -7.50 & \pm & 0.04 & -41.79 & \pm & 0.31 & 9.91 & $23 / 4 / 2015$ & -8.25 & \pm & 0.13 & -43.81 & \pm & 0.09 & 13.62 \\
\hline AT-G394 & $18 / 10 / 2014$ & -7.04 & \pm & 0.07 & -41.06 & \pm & 0.30 & 11.16 & $22 / 4 / 2015$ & -6.43 & \pm & 0.05 & -37.41 & \pm & 0.27 & 13.86 \\
\hline AT-G41 & $18 / 10 / 2014$ & -7.35 & \pm & 0.02 & -43.17 & \pm & 0.09 & 11.92 & $23 / 4 / 2015$ & -7.18 & \pm & 0.29 & -41.22 & \pm & 0.27 & 14.93 \\
\hline AT-G437 & $18 / 10 / 2014$ & -7.48 & \pm & 0.03 & -44.34 & \pm & 0.14 & 12.56 & $23 / 4 / 2015$ & - & \pm & - & - & \pm & - & - \\
\hline AT-G43A & $18 / 10 / 2014$ & -7.24 & \pm & 0.15 & -42.03 & \pm & 0.50 & 11.27 & $22 / 4 / 2015$ & -8.58 & \pm & 0.47 & -46.46 & \pm & 0.30 & 15.04 \\
\hline AT-G44 & $18 / 10 / 2014$ & -8.49 & \pm & 0.05 & -49.67 & \pm & 0.24 & 13.58 & $23 / 4 / 2015$ & -8.05 & \pm & 0.20 & -47.57 & \pm & 0.02 & 18.12 \\
\hline AT-G46 & $18 / 10 / 2014$ & -7.43 & \pm & 0.04 & -43.45 & \pm & 0.18 & 11.86 & $22 / 4 / 2015$ & -7.60 & \pm & 0.36 & -43.43 & \pm & 0.34 & 15.62 \\
\hline AT-G46A & $18 / 10 / 2014$ & -7.58 & \pm & 0.12 & -44.58 & \pm & 0.47 & 12.39 & $23 / 4 / 2015$ & -6.91 & \pm & 0.29 & -41.11 & \pm & 0.66 & 15.83 \\
\hline AT-G484 & $18 / 10 / 2014$ & -6.66 & \pm & 0.01 & -41.03 & \pm & 0.05 & 12.73 & $22 / 4 / 2015$ & -7.54 & \pm & 0.17 & -44.77 & \pm & 0.59 & 17.19 \\
\hline AT-G504 & $18 / 10 / 2014$ & -7.15 & \pm & 0.04 & -42.02 & \pm & 0.23 & 11.61 & $22 / 4 / 2015$ & -9.17 & \pm & 0.42 & -47.18 & \pm & 0.40 & 13.63 \\
\hline AT-G506 & $18 / 10 / 2014$ & -8.14 & \pm & 0.03 & -45.95 & \pm & 0.35 & 11.36 & $23 / 4 / 2015$ & -7.39 & \pm & 0.27 & -44.28 & \pm & 0.47 & 17.24 \\
\hline AT-G530 & $19 / 10 / 2014$ & -6.95 & \pm & 0.10 & -42.35 & \pm & 0.58 & 12.82 & $23 / 4 / 2015$ & -6.51 & \pm & 0.59 & -4.79 & \pm & 0.28 & -19.04 \\
\hline AT-G536 & $19 / 10 / 2014$ & -6.87 & \pm & 0.06 & -41.22 & \pm & 0.30 & 12.03 & $22 / 4 / 2015$ & -8.64 & \pm & 0.48 & -49.13 & \pm & 0.33 & 17.51 \\
\hline AT-G54 & $19 / 10 / 2014$ & -8.66 & \pm & 0.10 & -48.84 & \pm & 0.50 & 12.02 & $23 / 4 / 2015$ & -9.45 & \pm & 0.08 & -49.30 & \pm & 0.22 & 14.71 \\
\hline AT-G556 & $19 / 10 / 2014$ & -7.71 & \pm & 0.09 & -46.03 & \pm & 0.43 & 13.27 & $23 / 4 / 2015$ & -8.13 & \pm & 0.18 & -45.39 & \pm & 0.31 & 15.62 \\
\hline AT-G581 & $19 / 10 / 2014$ & -7.51 & \pm & 0.05 & -42.45 & \pm & 0.06 & 10.55 & $23 / 4 / 2015$ & -7.02 & \pm & 0.24 & -41.14 & \pm & 0.35 & 15.45 \\
\hline AT-G59 & $19 / 10 / 2014$ & -7.40 & \pm & 0.18 & -41.99 & \pm & 0.27 & 10.55 & $23 / 4 / 2015$ & -6.93 & \pm & 0.10 & -40.72 & \pm & 0.37 & 15.37 \\
\hline AT-G600 & $19 / 10 / 2014$ & -7.42 & \pm & 0.08 & -42.35 & \pm & 0.26 & 10.82 & $22 / 4 / 2015$ & -7.67 & \pm & 0.18 & -42.27 & \pm & 0.36 & 14.19 \\
\hline AT-G609 & $19 / 10 / 2014$ & -6.90 & \pm & 0.03 & -42.81 & \pm & 0.10 & 13.50 & $22 / 4 / 2015$ & -7.91 & \pm & 0.18 & -42.50 & \pm & 0.01 & 13.55 \\
\hline AT-G62 & $19 / 10 / 2014$ & -6.38 & \pm & 0.07 & -39.00 & \pm & 0.08 & 11.90 & $22 / 4 / 2015$ & -7.07 & \pm & 0.28 & -40.40 & \pm & 0.46 & 14.52 \\
\hline AT-G633 & $19 / 10 / 2014$ & -7.49 & \pm & 0.03 & -42.84 & \pm & 0.29 & 11.00 & $22 / 4 / 2015$ & -7.71 & \pm & 0.16 & -43.33 & \pm & 0.14 & 15.11 \\
\hline AT-G646 & $19 / 10 / 2014$ & -6.99 & \pm & 0.05 & -41.76 & \pm & 0.23 & 12.06 & $23 / 4 / 2015$ & -7.81 & \pm & 0.13 & -43.13 & \pm & 0.41 & 14.55 \\
\hline AT-G68 & $19 / 10 / 2014$ & -6.97 & \pm & 0.03 & -40.53 & \pm & 0.09 & 10.89 & $23 / 4 / 2015$ & -7.31 & \pm & 0.09 & -41.99 & \pm & 0.60 & 15.23 \\
\hline AT-G99 & $19 / 10 / 2014$ & -7.90 & \pm & 0.04 & -45.11 & \pm & 0.20 & 11.53 & $22 / 4 / 2015$ & -7.32 & \pm & 0.19 & -43.56 & \pm & 0.24 & 16.77 \\
\hline AT-S48 & $19 / 10 / 2014$ & -7.38 & \pm & 0.03 & -42.75 & \pm & 0.17 & 11.40 & $22 / 4 / 2015$ & -6.48 & & 0.16 & -39.79 & & 0.29 & 16.08 \\
\hline
\end{tabular}

Table $2 \delta^{18} \mathrm{O}, \delta \mathrm{D}$ and d-excess values for rainwater sampling sites

\begin{tabular}{|c|c|c|c|c|c|c|c|c|c|c|c|c|c|c|c|c|}
\hline ID & Sampling Date & $\delta^{18} 0$ & $(\% 0$ & & $\delta \mathrm{D}(\%$ & & & d-excess $(\% 0)$ & Sampling Date & $\delta^{18} 0$ & (\%o & & $\delta \mathrm{D}(\%$ & & & d-excess $(\% 0)$ \\
\hline RS1 & Oct-16 & -6.91 & \pm & 0.03 & -41.49 & \pm & 0.11 & 11.50 & Ian-17 & -6.98 & \pm & 0.04 & -41.90 & \pm & 0.14 & 11.41 \\
\hline RS2 & Oct-16 & -5.67 & \pm & 0.05 & -38.74 & \pm & 0.18 & 14.13 & Ian-17 & -5.73 & \pm & 0.06 & -39.13 & \pm & 0.23 & 14.10 \\
\hline RS3 & Oct-16 & -7.11 & \pm & 0.02 & -44.79 & \pm & 0.19 & 13.93 & Ian-17 & -7.18 & \pm & 0.03 & -45.24 & \pm & 0.24 & 13.86 \\
\hline RS4 & Oct-16 & -5.82 & \pm & 0.01 & -38.44 & \pm & 0.21 & 13.18 & Ian-17 & -5.88 & \pm & 0.01 & -38.82 & \pm & 0.26 & 13.14 \\
\hline RS5 & Oct-16 & -6.09 & \pm & 0.08 & -38.79 & \pm & 0.27 & 12.36 & Ian-17 & -6.15 & \pm & 0.10 & -39.18 & \pm & 0.34 & 12.30 \\
\hline RS6 & Oct-16 & -6.59 & \pm & 0.07 & -40.21 & \pm & 0.29 & 11.61 & Ian-17 & -6.66 & \pm & 0.09 & -40.61 & \pm & 0.36 & 11.53 \\
\hline RS7 & Oct-16 & -7.26 & \pm & 0.04 & -45.67 & \pm & 0.11 & 14.16 & Ian-17 & -7.33 & \pm & 0.05 & -46.13 & \pm & 0.14 & 14.08 \\
\hline RS8 & Oct-16 & -7.19 & \pm & 0.02 & -45.18 & \pm & 0.09 & 13.98 & Ian-17 & -7.26 & \pm & 0.03 & -45.63 & \pm & 0.11 & 13.90 \\
\hline RS9 & Oct-16 & -6.51 & \pm & 0.09 & -39.16 & \pm & 0.07 & 10.91 & Ian-17 & -6.58 & \pm & 0.11 & -39.55 & \pm & 0.09 & 10.82 \\
\hline RS10 & Oct-16 & -7.05 & \pm & 0.04 & -44.11 & \pm & 0.14 & 13.51 & Ian-17 & -7.12 & \pm & 0.05 & -44.55 & \pm & 0.18 & 13.43 \\
\hline RS11 & Oct-16 & -8.18 & \pm & 0.08 & -48.71 & \pm & 0.13 & 13.21 & Ian-17 & -8.26 & \pm & 0.10 & -49.20 & \pm & 0.16 & 13.09 \\
\hline RS12 & Oct-16 & -6.78 & \pm & 0.07 & -40.79 & \pm & 0.19 & 11.36 & Ian-17 & -6.85 & \pm & 0.09 & -41.20 & \pm & 0.24 & 11.27 \\
\hline RS13 & Oct-16 & -5.91 & \pm & 0.07 & -38.69 & \pm & 0.21 & 13.04 & Ian-17 & -5.97 & \pm & 0.09 & -39.08 & \pm & 0.26 & 12.99 \\
\hline RS14 & Oct-16 & -7.31 & \pm & 0.05 & -46.09 & \pm & 0.22 & 14.36 & Ian-17 & -7.38 & \pm & 0.06 & -46.55 & \pm & 0.28 & 14.29 \\
\hline RS15 & Oct-16 & -7.04 & \pm & 0.02 & -42.89 & \pm & 0.28 & 12.34 & Ian-17 & -7.11 & \pm & 0.03 & -43.32 & \pm & 0.35 & 12.25 \\
\hline RS16 & Oct-16 & -7.46 & \pm & 0.03 & -47.12 & \pm & 0.31 & 14.74 & Ian-17 & -7.53 & \pm & 0.04 & -47.59 & \pm & 0.39 & 14.66 \\
\hline RS17 & Oct-16 & -7.18 & \pm & 0.01 & -43.56 & \pm & 0.24 & 12.40 & Ian-17 & -7.25 & \pm & 0.01 & -44.00 & \pm & 0.30 & 12.31 \\
\hline RS18 & Oct-16 & -7.52 & \pm & 0.04 & -47.88 & \pm & 0.36 & 15.24 & Ian-17 & -7.60 & \pm & 0.05 & -48.36 & \pm & 0.45 & 15.17 \\
\hline RS19 & Oct-16 & -8.49 & \pm & 0.05 & -49.85 & \pm & 0.19 & 13.00 & Ian-17 & -8.57 & \pm & 0.06 & -50.35 & \pm & 0.24 & 12.88 \\
\hline RS20 & Oct-16 & -8.67 & \pm & 0.08 & -50.07 & \pm & 0.15 & 12.44 & Ian-17 & -8.76 & \pm & 0.10 & -50.57 & \pm & 0.19 & 12.30 \\
\hline RS21 & Oct-16 & -8.33 & \pm & 0.10 & -49.29 & \pm & 0.13 & 13.14 & Ian-17 & -8.41 & \pm & 0.13 & -49.78 & \pm & 0.16 & 13.02 \\
\hline RS22 & Oct-16 & -6.27 & \pm & 0.12 & -39.27 & \pm & 0.18 & 12.06 & Ian-17 & -6.33 & \pm & 0.15 & -39.66 & \pm & 0.23 & 11.99 \\
\hline RS23 & Oct-16 & -6.14 & \pm & 0.09 & -39.11 & \pm & 0.17 & 12.46 & Ian-17 & -6.20 & \pm & 0.11 & -39.50 & \pm & 0.21 & 12.40 \\
\hline RS24 & Oct-16 & -6.87 & \pm & 0.08 & -42.21 & \pm & 0.19 & 12.39 & Ian-17 & -6.94 & \pm & 0.10 & -42.63 & \pm & 0.24 & 12.31 \\
\hline RS25 & Oct-16 & -9.24 & \pm & 0.06 & -50.27 & \pm & 0.09 & 10.17 & Ian-17 & -9.33 & \pm & 0.08 & -50.77 & \pm & 0.11 & 9.99 \\
\hline RS26 & Oct-16 & -7.38 & \pm & 0.07 & -46.54 & \pm & 0.10 & 14.51 & Ian-17 & -7.45 & \pm & 0.09 & -47.01 & \pm & 0.13 & 14.43 \\
\hline RS27 & Oct-16 & -7.66 & \pm & 0.07 & -48.11 & \pm & 0.14 & 14.87 & Ian-17 & -7.74 & \pm & 0.09 & -48.59 & \pm & 0.18 & 14.78 \\
\hline RS1 & Mar-17 & -7.26 & \pm & 0.03 & -43.56 & \pm & 0.12 & 11.57 & May-17 & -7.15 & \pm & 0.04 & -42.94 & \pm & 0.14 & 11.55 \\
\hline RS2 & Mar-17 & -5.95 & \pm & 0.06 & -40.68 & \pm & 0.20 & 14.42 & May-17 & -5.87 & \pm & 0.07 & -40.10 & \pm & 0.23 & 14.33 \\
\hline RS3 & Mar-17 & -7.47 & \pm & 0.02 & -47.03 & \pm & 0.21 & 14.11 & May-17 & -7.36 & \pm & 0.03 & -46.36 & \pm & 0.25 & 14.05 \\
\hline RS4 & Mar-17 & -6.11 & \pm & 0.01 & -40.36 & \pm & 0.24 & 13.41 & May-17 & -6.02 & \pm & 0.01 & -39.79 & \pm & 0.27 & 13.34 \\
\hline RS5 & Mar-17 & -6.39 & \pm & 0.09 & -40.73 & \pm & 0.30 & 12.53 & May-17 & -6.30 & \pm & 0.11 & -40.15 & \pm & 0.35 & 12.48 \\
\hline RS6 & Mar-17 & -6.92 & \pm & 0.08 & -42.22 & \pm & 0.33 & 11.71 & May-17 & -6.82 & \pm & 0.10 & -41.62 & \pm & 0.38 & 11.67 \\
\hline RS7 & Mar-17 & -7.62 & \pm & 0.05 & -47.95 & \pm & 0.12 & 14.34 & May-17 & -7.51 & \pm & 0.06 & -47.27 & \pm & 0.14 & 14.28 \\
\hline RS8 & Mar-17 & -7.55 & \pm & 0.02 & -47.44 & \pm & 0.10 & 14.15 & May-17 & -7.44 & \pm & 0.03 & -46.76 & \pm & 0.12 & 14.09 \\
\hline RS9 & Mar-17 & -6.84 & \pm & 0.10 & -41.12 & \pm & 0.08 & 10.97 & May-17 & -6.74 & \pm & 0.13 & -40.53 & \pm & 0.09 & 10.95 \\
\hline RS10 & Mar-17 & -7.40 & \pm & 0.05 & -46.32 & \pm & 0.16 & 13.67 & May-17 & -7.30 & \pm & 0.06 & -45.65 & \pm & 0.18 & 13.62 \\
\hline RS11 & Mar-17 & -8.59 & \pm & 0.09 & -51.15 & \pm & 0.15 & 13.27 & May-17 & -8.47 & \pm & 0.11 & -50.41 & \pm & 0.17 & 13.25 \\
\hline
\end{tabular}




\begin{tabular}{|c|c|c|c|c|c|c|c|c|c|c|c|c|c|c|c|c|}
\hline \multirow{2}{*}{$\frac{\mathrm{ID}}{\mathrm{RS} 12}$} & \multirow{2}{*}{$\begin{array}{l}\text { Sampling Date } \\
\text { Mar-17 }\end{array}$} & \multicolumn{3}{|c|}{$\delta^{18} 0(\%)$} & \multicolumn{3}{|c|}{$\delta \mathrm{D}(\% 0)$} & \multirow{2}{*}{$\begin{array}{l}\text { d-excess }(\% 0) \\
11.43\end{array}$} & \multirow{2}{*}{$\begin{array}{l}\text { Sampling Date } \\
\text { May-17 }\end{array}$} & \multicolumn{3}{|c|}{$\delta^{18} 0(\% 0)$} & \multicolumn{3}{|c|}{$\delta \mathrm{D}(\% 0)$} & \multirow{2}{*}{$\begin{array}{l}\text { d-excess }(\% 0) \\
11.41\end{array}$} \\
\hline & & -7.12 & \pm & 0.08 & -42.83 & \pm & 0.21 & & & -7.02 & \pm & 0.10 & -42.22 & \pm & 0.25 & \\
\hline RS13 & Mar-17 & -6.21 & \pm & 0.08 & -40.62 & \pm & 0.24 & 13.26 & May-17 & -6.12 & \pm & 0.10 & -40.04 & \pm & 0.27 & 13.19 \\
\hline RS14 & Mar-17 & -7.68 & \pm & 0.06 & -48.39 & \pm & 0.25 & 14.55 & May-17 & -7.57 & \pm & 0.07 & -47.70 & \pm & 0.29 & 14.49 \\
\hline RS15 & Mar-17 & -7.39 & \pm & 0.02 & -45.03 & \pm & 0.32 & 12.44 & Мay-17 & -7.29 & \pm & 0.03 & -44.39 & \pm & 0.36 & 12.40 \\
\hline RS16 & Mar-17 & -7.83 & \pm & 0.03 & -49.48 & \pm & 0.35 & 14.93 & May-17 & -7.72 & \pm & 0.04 & -48.77 & \pm & 0.40 & 14.87 \\
\hline RS17 & Mar-17 & -7.54 & \pm & 0.01 & -45.74 & \pm & 0.27 & 12.49 & May-17 & -7.43 & \pm & 0.01 & -45.08 & \pm & 0.31 & 12.46 \\
\hline RS18 & Mar-17 & -7.90 & \pm & 0.05 & -50.27 & \pm & 0.41 & 15.45 & May-17 & -7.78 & \pm & 0.06 & -49.56 & \pm & 0.47 & 15.39 \\
\hline RS19 & Mar-17 & -8.91 & \pm & 0.06 & -52.34 & \pm & 0.21 & 13.03 & May-17 & -8.79 & \pm & 0.07 & -51.59 & \pm & 0.25 & 13.02 \\
\hline RS20 & Mar-17 & -9.10 & \pm & 0.09 & -52.57 & \pm & 0.17 & 12.43 & May-17 & -8.97 & \pm & 0.11 & -51.82 & \pm & 0.20 & 12.43 \\
\hline RS21 & Mar-17 & -8.75 & \pm & 0.11 & -51.75 & \pm & 0.15 & 13.18 & May-17 & -8.62 & \pm & 0.14 & -51.02 & \pm & 0.17 & 13.17 \\
\hline RS22 & Mar-17 & -6.58 & \pm & 0.14 & -41.23 & \pm & 0.20 & 12.20 & May-17 & -6.49 & \pm & 0.17 & -40.64 & \pm & 0.23 & 12.16 \\
\hline RS23 & Mar-17 & -6.45 & \pm & 0.10 & -41.07 & \pm & 0.19 & 12.63 & May-17 & -6.35 & \pm & 0.13 & -40.48 & \pm & 0.22 & 12.58 \\
\hline $\mathrm{RS} 24$ & Mar-17 & -7.21 & \pm & 0.09 & -44.32 & \pm & 0.21 & 12.51 & May-17 & -7.11 & \pm & 0.11 & -43.69 & \pm & 0.25 & 12.47 \\
\hline RS25 & Mar-17 & -9.70 & \pm & 0.07 & -52.78 & \pm & 0.10 & 10.00 & May-17 & -9.56 & \pm & 0.08 & -52.03 & \pm & 0.12 & 10.05 \\
\hline RS26 & Mar-17 & -7.75 & \pm & 0.08 & -48.87 & \pm & 0.11 & 14.69 & May-17 & -7.64 & \pm & 0.10 & -48.17 & \pm & 0.13 & 14.64 \\
\hline RS27 & Mar-17 & -8.04 & \pm & 0.08 & -50.52 & \pm & 0.16 & 15.05 & May-17 & -7.93 & \pm & 0.10 & -49.79 & \pm & 0.18 & 14.99 \\
\hline
\end{tabular}
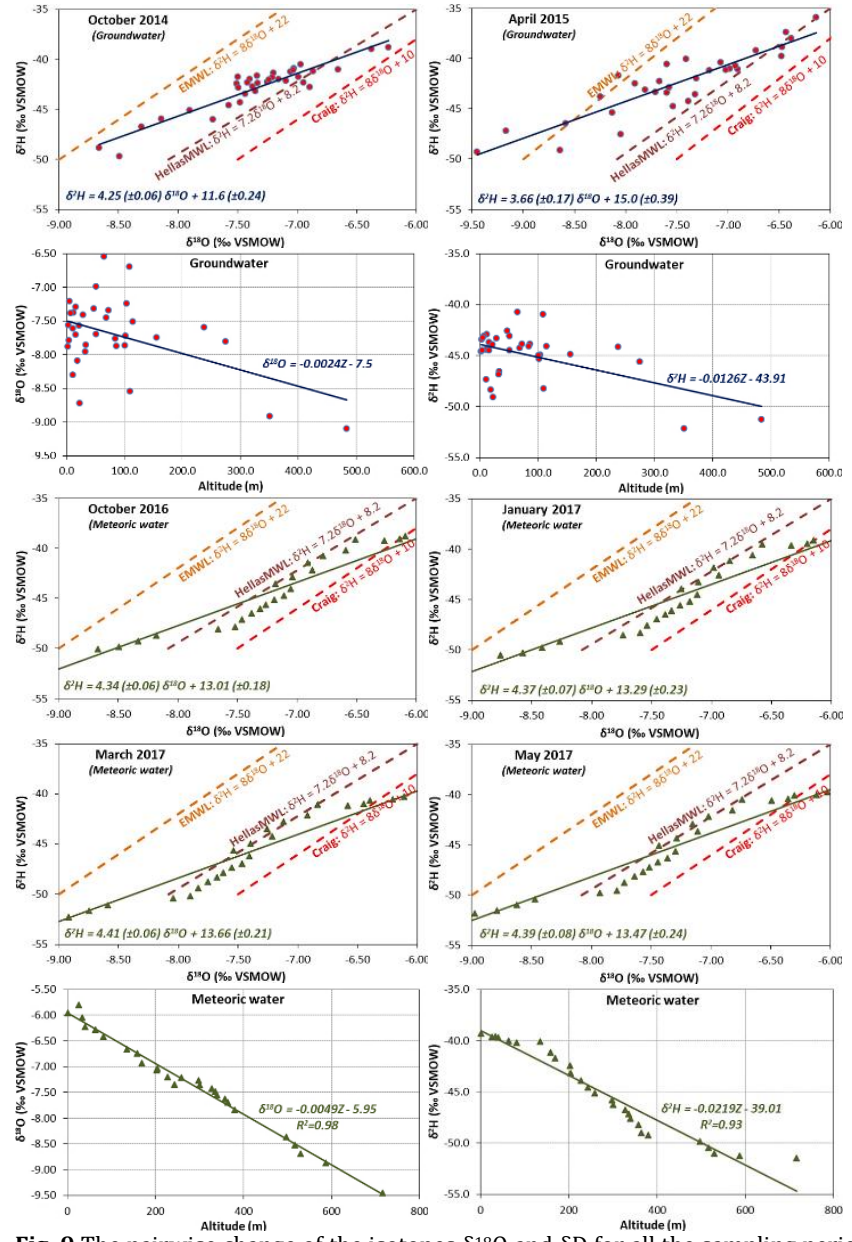

Fig. 9 The pairwise change of the isotopes $\delta^{18} 0$ and $\delta \mathrm{D}$ for all the sampling periods, as well as the correlation between the altitude and the mean values of $\delta^{180}$ and $\delta \mathrm{D}$ both for groundwater and precipitation
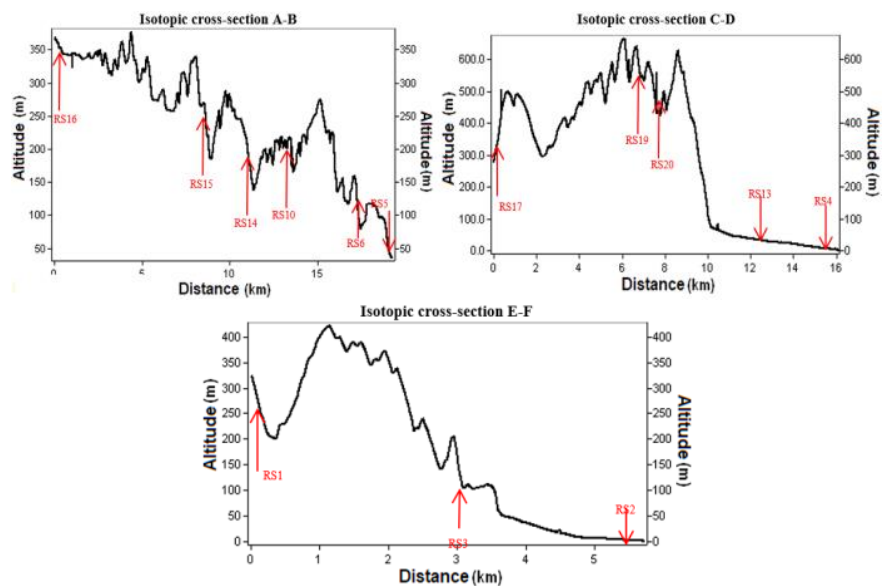

Fig. 10 Isotopic cross-sections showing the changes of $\delta^{18} 0$ and $\delta \mathrm{D}$ values of the meteoric water with altitude and shoreline distance https://doi.org/10.30799/jespr.174.19050304
The combined approach of this factor with that of altitude was found through the isotopic cross-sections (Fig. 10) heading from the mainland to the coastline (Gulf of Atalanti), at which the $\delta^{18} 0$ value of each rainfall collector was recorded.

Based on the results from the rain collectors within the basin under study, the Local Meteoric Water Line (LMWL) was approached, based on data that have been less affected by evaporation processes, resulting in the following equation,

\section{$\delta \mathrm{D}=4.3 \delta^{180}+12.32 \%$ (V-SMOW)}

This line relatively deviated from the line made for Greece by Argiriou and Lykoudis [44]. The study of stable isotopes in groundwater showed that the majority of hydropoints (wells and boreholes) were characterized by a slight relative change in the value of $\delta^{18} 0$ with respect to time and season.

The mean groundwater isotope composition was used to draw conclusions about the average recharge altitude of each sampling point, while comparing the pair of $\delta^{18} 0-\delta \mathrm{D}$ values (groundwater sampling period of Oct-2014 and Apr-2015) with the Local Meteoric Water Line (LMWL) provided information about the origin of the groundwater and the salinization degree. At the same time, a comparison of this change with that of meteoric water may reinforce the above information or lead to a different interpretation, given that the isotopic composition of groundwater sometimes follows the change in the isotopic composition of precipitation (Fig. 11).

Groundwater mapping of the LMWL showed that the origin of almost all sites was meteoric with evidence of secondary evaporation processes, whereas the karstic spring of Tragana was found at the mixing zone of meteoric and sea water. The results of the analyses indicated a shift from the LMWL which obviously showed the effect of secondary processes. The slope of the line and d-excess continue to show the dominant effect of secondary processes on the alluvial aquifer, but to a lesser degree. In order to determine the average groundwater recharge altitude at each sampling site, the values of $\delta^{18} 0$ with the altitude for all pairs of values are shown in Table 3.

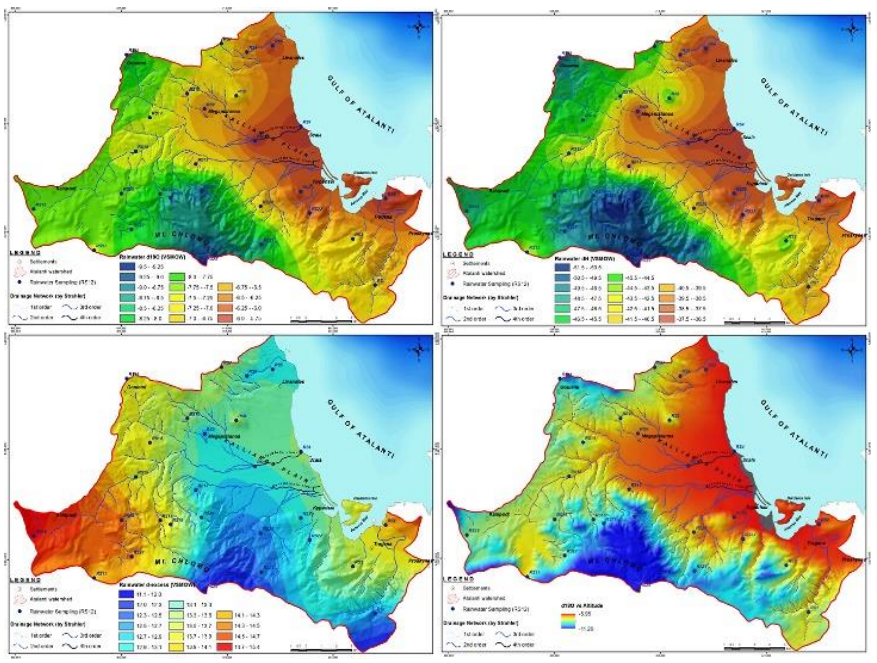

Fig. 11 Precipitation $\delta^{18} 0$ (left), $\delta D$ (right), d-excess (down left) spatial distribution based on the rain samples' isotopic composition and rainwater $\delta^{18} 0$ vs altitude (down right) based on the simple linear regression analysis 
Table 3 Estimated groundwater recharge altitude ( $m$ a.s.l.) from the isotope groundwater sampling sites

\begin{tabular}{|c|c|c|c|c|c|c|c|}
\hline $\begin{array}{l}\text { Groundwater } \\
\text { Sampling } \\
\text { Point }\end{array}$ & $\begin{array}{l}\text { Altitude } \\
\text { (m a.s.l.) }\end{array}$ & $\begin{array}{l}\delta^{18} 0(\% \\
10 / 201 \\
04 / 201\end{array}$ & & $\begin{array}{l}\text { Mean } \\
\text { value } \\
\delta^{18} 0 \\
(\% 0)\end{array}$ & $\begin{array}{l}\text { Recha } \\
\text { Altituc } \\
\text { (m a.s. } \\
10 / 20 \\
04 / 20\end{array}$ & & $\begin{array}{l}\text { Estimated } \\
\text { Mean } \\
\text { Recharge } \\
\text { Altitude } \\
\text { (m a.s.l.) }\end{array}$ \\
\hline $07 / G 5$ & 65.1 & -6.23 & -6.98 & -6.61 & 57.6 & 210.9 & 134.2 \\
\hline AT-G172 & 3.5 & -7.20 & -6.14 & -6.67 & 255.4 & 38.4 & 146.9 \\
\hline AT-G189 & 29.1 & -7.05 & -7.60 & -7.33 & 225.5 & 336.5 & 281.0 \\
\hline AT-G206 & 10.9 & -7.25 & -6.47 & -6.86 & 265.7 & 106.7 & 186.2 \\
\hline AT-G231 & 12.0 & -7.03 & -7.41 & -7.22 & 219.9 & 298.5 & 259.2 \\
\hline AT-G28 & 16.1 & -7.34 & -7.58 & -7.46 & 282.9 & 332.1 & 307.5 \\
\hline AT-G305 & 51.0 & -7.33 & -8.07 & -7.70 & 281.9 & 432.8 & 357.3 \\
\hline AT-G320 & 21.8 & -7.21 & -6.73 & -6.97 & 256.5 & 159.0 & 207.8 \\
\hline AT-G34 & 68.5 & -7.10 & - & -7.10 & 234.0 & - & 234.0 \\
\hline AT-G355 & 23.3 & -8.31 & -6.38 & -7.35 & 481.0 & 88.7 & 284.9 \\
\hline AT-G38 & 86.0 & -7.50 & -8.25 & -7.87 & 316.5 & 468.9 & 392.7 \\
\hline AT-G394 & 7.1 & -7.04 & -6.43 & -6.73 & 221.5 & 98.9 & 160.2 \\
\hline AT-G41 & 102.2 & -7.35 & -7.18 & -7.27 & 286.3 & 251.4 & 268.8 \\
\hline AT-G437 & 33.7 & -7.48 & - & -7.48 & 312.0 & - & 312.0 \\
\hline AT-G43A & 238.0 & -7.24 & -8.58 & -7.91 & 262.4 & 537.6 & 400.0 \\
\hline AT-G44 & 350.9 & -8.49 & -8.05 & -8.27 & 519.0 & 427.7 & 473.3 \\
\hline AT-G46 & 274.8 & -7.43 & -7.60 & -7.52 & 303.0 & 336.2 & 319.6 \\
\hline AT-G46A & 32.7 & -7.58 & -6.91 & -7.24 & 331.9 & 195.1 & 263.5 \\
\hline AT-G484 & 51.0 & -6.66 & -7.54 & -7.10 & 144.4 & 323.7 & 234.0 \\
\hline AT-G504 & 115.0 & -7.15 & -9.17 & -8.16 & 245.8 & 656.3 & 451.0 \\
\hline AT-G506 & 110.0 & -8.14 & -7.39 & -7.76 & 446.6 & 293.2 & 369.9 \\
\hline AT-G530 & 16.1 & -6.95 & -6.51 & -6.73 & 203.6 & 114.3 & 159.0 \\
\hline AT-G536 & 5.1 & -6.87 & -8.64 & -7.75 & 187.4 & 549.0 & 368.2 \\
\hline AT-G54 & 483.9 & -8.66 & -9.45 & -9.06 & 554.0 & 714.7 & 634.4 \\
\hline AT-G556 & 18.6 & -7.71 & -8.13 & -7.92 & 358.7 & 445.6 & 402.1 \\
\hline AT-G581 & 2.7 & -7.51 & -7.02 & -7.26 & 317.6 & 218.3 & 268.0 \\
\hline AT-G59 & 84.6 & -7.40 & -6.93 & -7.16 & 295.4 & 199.4 & 247.4 \\
\hline AT-G600 & 4.3 & -7.42 & -7.67 & -7.55 & 299.7 & 351.6 & 325.6 \\
\hline AT-G609 & 104.0 & -6.90 & -7.91 & -7.40 & 193.2 & 399.8 & 296.5 \\
\hline AT-G62 & 109.1 & -6.38 & -7.07 & -6.72 & 87.0 & 228.6 & 157.8 \\
\hline AT-G633 & 101.4 & -7.49 & -7.71 & -7.60 & 314.7 & 359.6 & 337.2 \\
\hline AT-G646 & 72.6 & -6.99 & -7.81 & -7.40 & 212.3 & 379.1 & 295.7 \\
\hline AT-G68 & 47.6 & -6.97 & -7.31 & -7.14 & 208.9 & 277.6 & 243.2 \\
\hline AT-G99 & 10.7 & -7.90 & -7.32 & -7.61 & 398.4 & 279.4 & 338.9 \\
\hline AT-S48 & 155.9 & -7.38 & -6.48 & -6.93 & 290.9 & 108.0 & 199.5 \\
\hline
\end{tabular}

The collected rainfall samples were used to estimate the relationship between altitude and $\delta^{18} \mathrm{O}$ values by using the least squared equation approach (linear regression analysis). The average recharge zone altitude for each sampling site was estimated by using the following equation: $y$ $=a \cdot x+b$ where $y=$ the estimated average recharge zone altitude $(\mathrm{m}), a$ the slope of the least squared regression line connecting rainfall $\delta^{18} 0$ values and altitude, $x=$ the sampling points average $\delta^{18} 0$ value and $b$ the offset in $y$ axis of the least squared regression line. The particular recharge zone altitude estimations are quite approximated since the available data to ascertain the accuracy of those estimations are limited, however, combined with other information such as the geology and topography can provide the identification for the recharge zones. Then, the particularly outcome was combined with the recharge zone altitude estimations and the main geological properties of the area to identify common recharge areas and the potential limits of the respective aquifers.

A high dispersion in $\delta^{18} 0$ concentrations is observed at low altitudes due to the fact that these aquifers are enriched by isotopically lighter water through streamflow or lateral flows. In addition, the evaporation phenomena in the soil and subsoil zone at low altitudes are more intense and therefore, in some cases the water is isotopically enriched due to evaporation. According to what has been reported about the relation of $\delta^{18} 0$ with the altitude, the alluvial aquifer appears to be recharged directly from the area in which they develop surface or possibly lateral to karstic and marshy groundwater, coming from areas of higher altitude. The rest of the research area seems to be recharged exclusively by the areas where the aquifer-hosted formations are superficially developed. The AtalantiLivanates alluvial coastal aquifer is almost entirely recharged by water coming from higher altitudes. This water can be transported in two ways to the aquifer either by lateral groundwater recharge from the adjacent upstream aquifers or surface via the drainage network and by the flowing streams.

The alluvial aquifer had isotopically lighter water, which is due to the fact that these aquifers receive most of the enrichment from higher elevations. According to the linear relationship between $\delta^{18} 0$ and altitude and taking into account their strong correlation $\left(\mathrm{R}^{2}=0.98\right)$ it is possible to https://doi.org/10.30799/jespr.174.19050304 estimate the groundwater recharge altitude [52] based on the values measured at both sampling periods (Table 3 and Fig. 12). It is assumed that the sampling points located at the outskirts of the watershed are mainly recharged from high relative elevations outside the basin in contrast to the rest, which are predominantly within the sedimentary deposits, where the recharge area may have originated from areas within the catchment. High $\delta^{18} 0$ values, i.e. indicating an enrichment (near VSMOW), lead to the conclusion of groundwater origin through direct infiltration from meteoric water, which means that the groundwater flow is quite short, thus associated with local enrichment conditions.
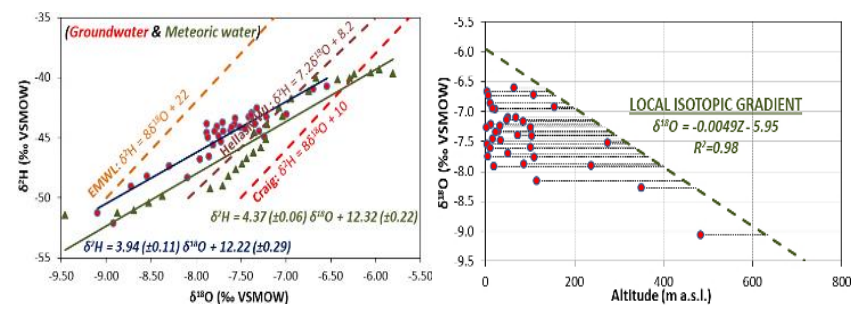

Fig. 12 The mean isotopic ratios' variation (left) of the $\delta^{18} 0$ and $\delta \mathrm{D}$ both for groundwater (blue solid line) and meteoric (green solid line) water. On the right, the observed $\delta^{18} 0$ values in groundwater vs the estimated mean recharge altitude (m a.s.l.) regarding the line of isotopic depletion (local vertical isotopic gradient) with altitude of the precipitation at different elevations

\subsection{Multivariate Statistical Approach}

In addition to the simple linear regression analysis, multiple regression analysis was also performed to define the weight percentage of each factor affecting the isotopic ratio values $[40,53]$. The criteria in developing the linear model were to select monitoring points unaffected by other factors that may cause isotopic fractionation in order to capture the groundwater infiltration. Groundwater data were compared to precipitation data, in order to define the origin of the groundwater and to investigate the existence of evaporation processes that might have altered the original isotope values of the samples.

Multiple linear regression analysis is a statistical tool that allows examining how multiple independent variables $\left(\mathrm{X}_{1}, \mathrm{X}_{2}, \ldots, \mathrm{X}_{\mathrm{n}}\right)$ are related to a dependent variable $(Y)$. Once identified how these multiple variables relate to a dependent variable, one can take information about all of the independent variables and use it to make much more powerful and accurate predictions. Adjust criteria for the multiple regression equation to the observed data are the correlation coefficient $\mathrm{R}$, the determination coefficient $\mathrm{R}^{2}$ and the adjusted $\mathrm{R}^{2}$. The aforementioned analysis took into account that $\delta^{18} \mathrm{O}$ and $\delta \mathrm{D}$ as dependent variables were a linear function of the rest isotopic independent variables based on Pearson's correlation matrix expressed as [54],

$Y=b_{0}+b_{1} X_{1}+b_{2} X_{2}+b_{3} X_{3}+b_{4} X_{4}+b_{5} X_{5}+b_{6} X_{6}+b_{7} X_{7}+b_{8} X_{8}+\varepsilon$

$\delta^{18} 0$ or $\delta \mathrm{D}=\mathrm{b}_{\mathrm{o}}+\mathrm{b}_{1}$ ELEV $+\mathrm{b}_{2}$ DIST $+\mathrm{b}_{3}$ LAT $+\mathrm{b}_{4}$ PREC $+\mathrm{b}_{5}$ TEMP $+\mathrm{b}_{6}$ AET

where, ELEV, DIST, LAT, PREC, TEMP and AET are the elevation, the shoreline distance, the latitude, the mean over-annual precipitation, the mean over-annual temperature and the mean over-annual actual evapotranspiration, respectively, $\varepsilon$ is the error, namely, the difference between the measured and predicted value of the dependent variable, $b_{0}$ is the constant, namely, the intercept and $b_{1 \ldots 6}$ are the multiple regression coefficients which describe the independent variables' influence.

In order to better understand the relationship between the isotopic ratios $\delta^{18} 0-\delta \mathrm{D}$ and the factors affecting their values, the linear correlation in tabular form (Tables 4 and 5) of both groundwater and meteoric water was studied. The stable isotope composition $\left(\delta^{18} 0\right)$ of groundwater was considered the response variable, whereas the driving factors of the stable isotope composition of precipitation (e.g. latitude, elevation, distance from the sea, precipitation amount, temperature, evapotranspiration) were considered the independent variables [10].

These tables showed that for the groundwater there was a good correlation of $\delta^{18} 0-\delta \mathrm{D}$ with altitude and mean over-annual rainfall and poor correlation with latitude, while for meteoric water all parameters showed good to very strong correlation except for latitude effect, which was expected due to the relative proximity of the sampling points (Fig. 13). It has to be noted that the tables below do not include the seasonal effect because the measured values of the isotopic ratios for both groundwater and meteoric water were for a few periods during a hydrological year, thus, no safe conclusions could be drawn as far as the seasonal effect is concerned. 
Table 4 Multivariate statistical analysis (by Pearson's correlation matrix) of the parameters affecting the isotopic ratios $\delta^{18} \mathrm{O}$ and $\delta \mathrm{D}$ in the groundwater

\begin{tabular}{|c|c|c|c|c|c|c|c|c|}
\hline Variables & $\delta^{18} \mathrm{O}$ & $\delta \mathrm{D}$ & Latitude & Distance & Altitude & $\begin{array}{l}\text { Precipi- } \\
\text { tation }\end{array}$ & Temp. & $\begin{array}{l}\text { Actual } \\
\text { Evapotr. }\end{array}$ \\
\hline$\overline{\delta^{18} 0}$ & 1 & & & & & & & \\
\hline$\delta \mathrm{D}$ & 0.669 & 1 & & & & & & \\
\hline Latitude & -0.216 & -0.235 & 1 & & & & & \\
\hline Distance & -0.425 & -0.357 & -0.279 & 1 & & & & \\
\hline Altitude & -0.636 & -0.534 & -0.017 & 0.841 & 1 & & & \\
\hline Precip. & -0.613 & -0.524 & -0.111 & 0.848 & 0.991 & 1 & & \\
\hline Temp. & 0.360 & 0.328 & 0.275 & -0.875 & -0.762 & -0.778 & 1 & \\
\hline $\begin{array}{l}\text { Actual } \\
\text { Evapotr. }\end{array}$ & -0.374 & -0.356 & -0.238 & 0.843 & 0.723 & 0.740 & -0.984 & 1 \\
\hline
\end{tabular}

Table 5 Multivariate statistical analysis (by Pearson's correlation matrix) of the parameters affecting the isotopic ratios $\delta^{18} 0$ and $\delta \mathrm{D}$ in the meteoric water

\begin{tabular}{lllllllll}
\hline Variables & $\delta^{18} \mathrm{O}$ & $\delta \mathrm{D}$ & Latitude & Distance & Altitude & $\begin{array}{l}\text { Precipi- } \\
\text { tation }\end{array}$ & Temp. $\begin{array}{l}\text { Actual } \\
\text { Evapotr. }\end{array}$ \\
\hline$\delta^{18} \mathrm{O}$ & 1 & & & & & & & \\
$\delta \mathrm{D}$ & 0.950 & 1 & & & & & & \\
Latitude & 0.299 & 0.259 & 1 & & & & & \\
Distance & -0.581 & -0.625 & -0.299 & 1 & & & & \\
Altitude & -0.993 & -0.964 & -0.280 & 0.558 & 1 & & & \\
Precip. & -0.925 & -0.943 & -0.388 & 0.694 & 0.921 & 1 & & \\
Temp. & 0.979 & 0.926 & 0.332 & -0.535 & -0.985 & -0.883 & 1 & \\
Actual & -0.945 & -0.950 & -0.324 & 0.669 & 0.939 & 0.979 & -0.901 & 1 \\
Evapotr. & & & & & & & \\
\hline
\end{tabular}

The applied statistical analysis resulted in the following linear equations for groundwater and meteoric water, respectively:

\subsubsection{Groundwater}

$$
\begin{array}{r}
\delta^{18} \mathrm{O}=125.92-0.004 \cdot \mathrm{ELEV}+0.013 \cdot \mathrm{DIST}-2.117 \cdot \mathrm{LAT}+0.002 \cdot \mathrm{PREC}- \\
1.573 \cdot \mathrm{TEMP}-0.054 \cdot \mathrm{AET} \\
\delta \mathrm{D}=1330.01+0.022 \cdot \mathrm{ELEV}+0.006 \cdot \mathrm{DIST}-28.25 \cdot \mathrm{LAT}-0.047 \cdot \mathrm{PREC}- \\
7.684 \cdot \mathrm{TEMP}-0.290 \cdot \mathrm{AET}
\end{array}
$$

Deleting the independent variable of latitude the above equations are transformed to,

$$
\begin{aligned}
& \delta^{18} \mathrm{O}=134.91-0.007 \cdot \mathrm{ELEV}+0.023 \cdot \mathrm{DIST}+0.003 \cdot \mathrm{PREC}-1.72 \cdot \mathrm{TEMP}- \\
& 0.06 \cdot \mathrm{AET} \\
& \delta \mathrm{D}=1338.21+0.023 \cdot \mathrm{ELEV}+0.008 \cdot \mathrm{DIST}-0.049 \cdot \mathrm{PREC}-7.713 \cdot \mathrm{TEMP}-
\end{aligned}
$$$$
0.291 \cdot \mathrm{AET}
$$

\subsubsection{Meteoric Water}

$$
\begin{gathered}
\delta^{18} \mathrm{O}=-16.61-0.004 \cdot \mathrm{ELEV}-0.004 \cdot \mathrm{DIST}+0.310 \cdot \mathrm{LAT}+0.002 \cdot \mathrm{PREC}+ \\
0.062 \cdot \mathrm{TEMP}-0.006 \cdot \mathrm{AET} \\
\delta \mathrm{D}=45.61-0.031 \cdot \mathrm{ELEV}-0.066 \cdot \mathrm{DIST}-1.067 \cdot \mathrm{LAT}-0.008 \cdot \mathrm{PREC}-
\end{gathered}
$$

2.608·TEMP - 0.013·AET

Deleting the independent variable of latitude the above equations are transformed to,

$$
\begin{aligned}
& \delta^{18} \mathrm{O}=-5.37-0.004 \cdot \mathrm{ELEV}-0.004 \cdot \mathrm{DIST}+0.003 \cdot \mathrm{PREC}+0.103 \cdot \mathrm{TEMP}- \\
& 0.006 \cdot \mathrm{AET} \\
& \delta \mathrm{D}=6.85-0.032 \cdot \mathrm{ELEV}-0.067 \cdot \mathrm{DIST}-0.007 \cdot \mathrm{PREC}-2.747 \cdot \mathrm{TEMP}-
\end{aligned}
$$
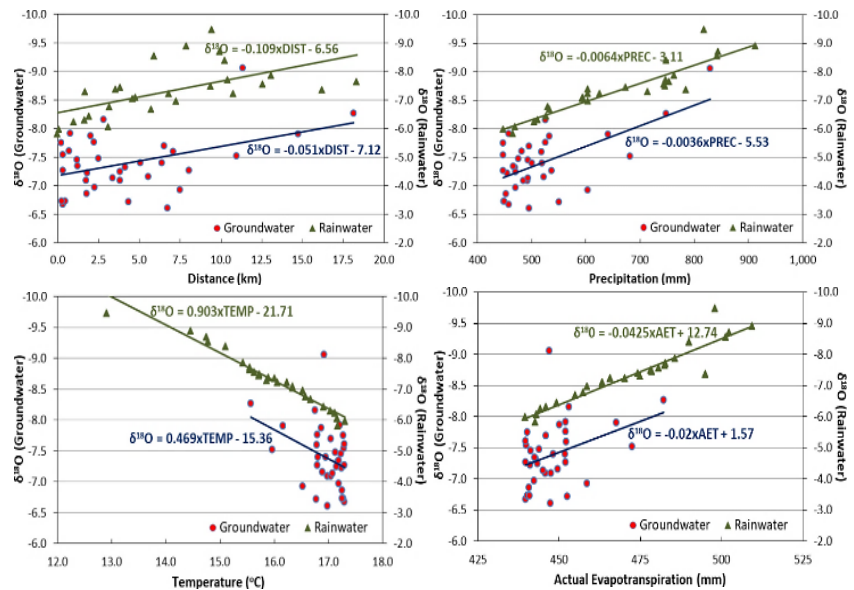

Fig. 13 Regression analysis between $\delta^{18} 0$ (for both groundwater and meteoric water) and atmospheric-geographical parameters https://doi.org/10.30799/jespr.174.19050304
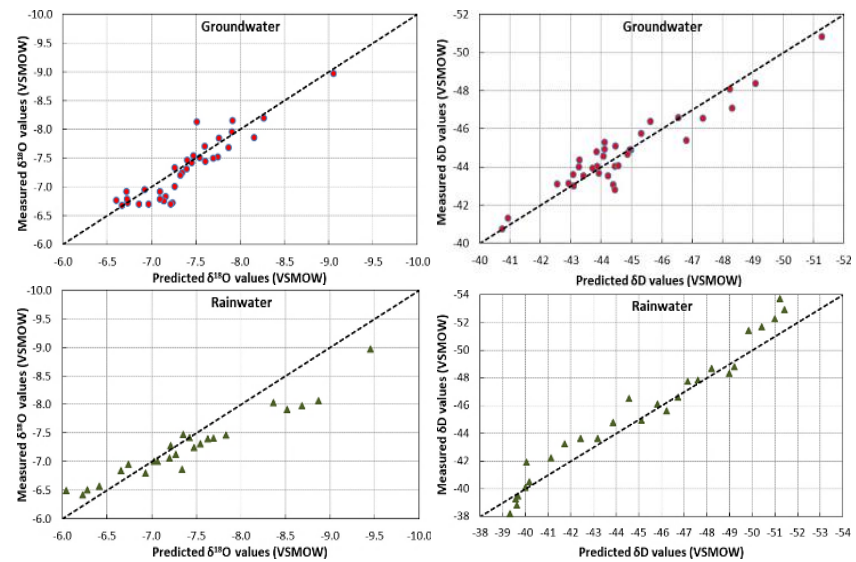

Fig. 14 The scatterplot between measured and predicted values of $\delta^{18} 0$ and $\delta D$ both for groundwater and precipitation. The black dashed line represents the equiline 1:1

The correlation coefficient $R$ is 0.936 , the determination coefficient $R^{2}$ equals to 0.921 which means that the model explained the $92.1 \%$ of the variance and the adjusted $\mathrm{R}^{2}$ is 0.919 meaning that the use of these factors as independent variables could accurately predict the dependent variable of $\delta^{18} 0$ and $\delta$ D (Fig. 14).

\section{Conclusion}

In the case study described above, the stable isotopic composition of precipitation and groundwater as well as the recharge mechanism of aquifers and the groundwater flow path by using $\delta^{18} 0$ and $\mathrm{D}$ values during the period 2014-2017 (36 groundwater samples and 27 rainfall ones) was examined and analyzed by studying their spatial distribution either independently or in comparison. The isotopic gradient defined in this study was $-0.437 \delta^{18} 0 \%$ per $100 \mathrm{~m}$ elevation. The results showed that the groundwater samples were of a meteoric origin in the Atalanti basin and the residence time was long enough. Also, the temporal variations caused by the meteoric recharge were negligible, in general. Moreover, the study showed that the stable isotopes compositions of precipitation decrease with increasing rainfall amount and air temperature. The isotopic ranges of the groundwaters were relatively smaller and more depleted than those of precipitation indicating that the groundwater mainly came from upstream precipitation. The inferred mean recharge altitude, as it was defined with the help of oxygen isotope ratios, was in agreement with the topographic contours (strong spatial coherence), geological and hydrogeological settings, according to in situ observations. The recharge contributing to groundwater appears to be derived from a mean elevation ranging from 150 to $750 \mathrm{~m}$ a.s.l. The relationship between $\delta^{18} \mathrm{O}$ and $\delta \mathrm{D}$, for precipitation and well water samples, showed shifts of both the slope and the d-excess (ranging values from 10 to $15 \%$ ) when compared to the world meteoric (WMWL), eastern mediterranean (EMWL) and Hellenic (HMWL) meteoric water lines suggesting the precipitation in the groundwater comes from the Mediterranean sea strongly affected by evaporation and secondary processes. The deviation of data points from the meteoric lines could be attributed to evaporation both during the rainfall and by surface runoff before infiltration. Furthermore, a predictive multilinear regression model for oxygen isotopic spatial patterns in groundwater and rainfall was developed using elevation, latitude, temperature, evapotranspiration and distance to the sea as predictive variables.

The applied model finally explained over $90 \%$ of the overall isotopic variance observed in rainfall and almost $80 \%$ in groundwater as far as the function mechanism is concerned. In conclusion, the use of isotopic methods in hydrogeology contributes significantly to the solution of problems and the examination of physical procedures that are difficult to deal with the conventional ways of study. The sampling campaign, however, should include more seasons and many more rainfall isotopic analyses so as to refine the relationship between the recharge altitude and the $\delta^{18} 0$ values.

\section{Acknowledgements}

The authors wish to express thanks to the Isotope Hydrology laboratory of the University of Darmstadt in Germany for the isotopic analyses $\left(\delta^{18} 0\right.$, $\delta \mathrm{D}$ ) of both groundwater and rainwater samples as well as the Hellenic National Meteorological Service (HNMS) and the Ministry of Environment and Energy for the meteorological stations' precipitation and temperature dataset of the regional area. 


\section{References}

[1] A. Antonakos, K. Nikas, Delineation of recharge areas of the aquifer systems of Corinthia prefecture by the use of isotopic evidence, Proceedings of the $13^{\text {th }}$ International Congress, Chania, 2013.

[2] W. Dansgaard, The abundance of 180 in atmospheric water and water vapour, Tellus. 5 (1953) 461-469.

[3] W. Dansgaard, Stable isotopes in precipitation, Tellus. 16 (1964) 436-468.

[4] J. Gat, Comments on the stable isotope method in regional groundwater investigations, Water Resour. Res. 7 (1971) 980-993.

[5] J. Gat, The isotopes of hydrogen and oxygen in precipitation, In. P. Fritz, J.Ch. Fontes, (Editors), Handbook of the environmental isotope geochemistry, Vol. 1, The Terrestrial Environment, Part A, Elsevier Scientific, Amsterdam, 1980, pp.21-47.

[6] J. Gat, I. Carmi, Evolution of the isotopic composition of atmospheric waters in the Mediterranean Sea area, J. Geophys. Res. 75 (1970) 3039-3048.

[7] I. Leontiadis, S. Vergis, T. Christodoulou, Isotope hydrology study of areas in Eastern Macedonia and Thrace, Northern Greece, Jour. Hydr. 182 (1996) 1-17.

[8] W. Mook, Introduction to isotope hydrology, Taylor \& Francis, 2005, p.288.

[9] S. Ahn, J. Kim, W. Kim, Environmental isotope studies on seawater intrusion into the southeastern coastal aquifer on Cheju Island, IAEA, Vienna, 1992.

[10] I. Clark, P. Fritz, Environmental isotopes in hydrogeology, Lewis Publishers, New York, 1997, p.328.

[11] J. Hoefs, Stable isotope geochemistry, Springer, Berlin, 2004, p.350.

[12] W. Lloyd, F. Howard, Environmental isotope studies related to groundwater flow and saline encroachment in the chalk aquifer of Lincolnshire, England, Isotope Hydrology, International Symposium on Isotope Hydrology, Int. Atomic Energy Agency, Vienna, 1979, pp.311-325.

[13] I. Lappas, Applied hydrogeological research in coastal aquifers, Case study of the coastal part of Atalanti region, Prefecture of Fthiotida, Ph.D. Thesis Dissertation, School of Mining and Metallurgical Engineering, National and Technical University of Athens, 2018, p.487.

[14] I. Lappas, I. Matiatos, Modelling of rainfall data using stochastic methods (Seasonal ARIMA), Case study of Atalanti meteorological station in Central Eastern Greece, Proceedings of the $13^{\text {th }}$ International Congress, Chania, 2013.

[15] I. Lappas, V. Tsioumas, V. Zorapas, Spatial - temporal analysis, variation and distribution of precipitation in the water district of Central - Eastern Greece, Bulletin of the Geological Society of Greece, Vol. XLVII, Proceedings of the $13^{\text {th }}$ International Congress, Chania, 2013.

[16] I. Lappas, V. Tsioumas, V. Zorapas, K. Kaloumenos, Estimation and surface distribution of climate indices in the water district of Central - Eastern Greece, Proceedings of the $10^{\text {th }}$ Hydrogeological Congress, Greece, 2014

[17] G. Maratos, K. Rigopoulos, A. Athanasiou, Geological maps of Atalanti and Livanates sheets, scale 1.50.000, Institute of Subsurface Geological Research, Atalanti, 1965.

[18] V. Karastathis, A. Ganas, J. Makris, J. Papoulia, P. Dafnis, E. Gerolymatou, G. Drakatos, The application of shallow seismic techniques in the study of active faults, The Atalanti normal fault, central Greece, J. Appl. Geophys. 62 (2007) 215-233.

[19] K. Makropoulos, V. Kouskouna, The 1894 April 20 and 27 Atalanti earthquakes. 100 years after - lessons learnt, XXIV European Seismological Comission (ESC), General Assembly, Athens Proc. 1 (1994) 61-67.

[20] S. Stiros, Th. Rondogianni, Recent vertical movements across the Atalandi fault zone (central Greece), Pure Appl. Geophys. 123 (1985) 837-848.

[21] N. Palivos, Geomorphological study of Atalanti area of Fthiotida prefecture, Ph.D. Thesis Dissertation, School of Sciences, Department of Geology, Athens, 2001.

[22] D. Pantosti, P. DeMartini, D. Papanastassiou, N. Palivos, F. Lemeille, et al., Geomorphological and paleoseismological studies of the Atalanti fault, XXVII Gen. Assembly of the Eur. Seism. Comiss., Lisbon Univ., Lisbon, 2000, p.73.

[23] D. Pantosti, P. De Martini, D. Papanastassiou, N. Palivos, F. Lemeille, G. Stavrakakis, A Re-appraisal of the 1894 Atalanti earthquake surface ruptures, Central Greece Bull. Seismol. Soc. Am. 91(4) (2001) 760-780.

[24] I. Matiatos, Hydrogeological and isotopic investigations in regions of Argolis peninsula, Ph.D. Thesis Dissertation, Department of Geology and Geoenvironment, National and Kapodistrian University of Athens, Greece, 2010, p.492.

[25] C. Kendall, G. Sklash, D. Bullen, Isotope tracers of water and solute sources in catchments, Solute modelling in catchment systems, John Wiley and Sons Ltd., New York, 1995, pp.61-303.

[26] P. Aggraval, J. Gat, K. Froehlich, Isotopes in the water cycle, Past, present and future of a developing science, Springer, Netherlands, 2005.
[27] H. Craig, Isotopic standards for carbon and oxygen and correction factors for mass spectrometric analysis of carbon dioxide, Geochim. Cosmochim. Acta 12 (1957) 133-149.

[28] H. Craig, Standard for reporting concentrations of deuterium and oxygen-18 in natural waters, Science 133 (1961) 1833-1934

[29] H. Craig, Isotopic variations in meteoric waters, Science, 133 (1961) 1702 1703.

[30] H. Craig, L. Gordon, Deuterium and oxygen-18 variation in the ocean and the marine atmosphere, In. E. Tongiorgi, (Ed.), Stable isotopes in oceanographic studies and paleotemperatures, Spoleto, 1965, pp.9-130.

[31] R. Gat, R. Gonfiantini, Stable isotope hydrology, deuterium and oxygen-18 in the water cycle, Technical Report Series No. 210, IAEA, Vienna, 1981.

[32] R. Gonfiantini, L. Araguas, Environmental isotope study of seawater intrusion. Intrusion mechanism in the aquifer, IGME, Madrid, I, 1988, 135-190.

[33] K. Rozanski, L. Araguás, R. Gonfiantini, Isotopic patters in modern global precipitation, in Climate Change in Continental Isotopic Records, Geophys. Monogr. Ser. 78 (1993) 1-36.

[34] G. Sappa, M. Barbieri, S. Ergul, F. Ferranti, Hydrogeological conceptual model of groundwater from carbonate aquifers using environmental isotopes $(180,2 \mathrm{H})$ and chemical tracers, A case study in Southern Latium Region, Central Italy, J. Water Resour. Protect. 4 (2012) 695-716.

[35] E. Souza, P. Galvão, R. Almeida, C. Pinheiro, M. Baessa, M. Cabral, Stable isotopes studies in the Urucu oil province, Amazon Region, Brazil, J. Water Resour Protect. 7 (2015) 131-142.

[36] S. Epstein, T. Mayeda, Variations of the 180/160 ratio in natural waters, Geochim. Cosmochim. Acta 4 (1953) 213-221.

[37] E. Eriksson, Isotopes in hydro-meteorology, In. Isotopes in hydrology, IAEA, Vienna, 1967, pp.21-33.

[38] I. Friedman, Deuterium content of natural waters and other substances, Geochim. Cosmochim. Acta 4 (1953) 89-103.

[39] C. Kendall, A. Caldwell, Fundamentals of isotope geochemistry, Isotope tracers in catchment hydrology, Elsevier Science, Amsterdam, 1998, pp.51-86.

[40] C. Kendall, T. Coplen, Distribution of oxygen-18 and deuterium in river waters across the United States, Hydrol. Proces. 15 (2001) 1363-1393.

[41] G. Kallergis, I. Leontiadis, Isotope hydrology study of Kalamos Attikis and Asopos river plain areas in Greece, J. Hydrol. 60 (1983) 209-225.

[42] E. Zagana, M. Obeidat, Ch. Kuells, P. Udluft, Chloride, hydrochemical and isotopes methods of groundwater recharge estimation in eastern Mediterranean - A case study in Jordan, Hydrol. Proces. 21(16) (2007) 21122123

[43] H. Celle-Jeanton, Y. Travi, B. Blavoux, Isotopic typology of the precipitation in the Western Mediterranean region at three different time scales, Geophys. Res. Lett. 28(7) (2001) 1215-1218.

[44] A. Argiriou, S. Lykoudis, Isotopic composition of precipitation in Greece, Jour. Hydrol. 327 (2006) 486-495.

[45] E. Dotsika, S. Lykoudis, D. Poutoukis, Spatial distribution of the isotopic composition of precipitation and spring water in Greece, Global Planetary Change 71 (2010) 141-149.

[46] E. Dotsika, D. Poutoukis, B. Raco, D. Psomiadis, Stable isotope composition of Hellenic bottled waters, J. Geochem. Explor. 107 (2010) 299-304

[47] S. Lykoudis, A. Argiriou, E. Dotsika, Spatially interpolated time series of $\delta 180$ in Eastern Mediterranean precipitation, Global Planetary Change 71 (2010) 150-159.

[48] I. Matiatos, A. Alexopoulos, N. Zouridakis, Use of stable isotopes in the determination of the mean altitude of recharge and the investigation of function mechanism of spring waters in Argolis peninsula (Greece) Proceedings of the $12^{\text {th }}$ International Congress, Patra, 2010.

[49] I. Matiatos, A. Alexopoulos, Application of stable isotopes and hydrochemical analysis in groundwater aquifers of Argolis Peninsula (Greece), Isotope. Environ. Health Stud. 47(4) (2011) 512-529.

[50] I. Matiatos, A. Alexopoulos, Analysis of temporal hydrochemical and isotopic variations in spring waters of eastern Peloponnesus (Greece), Proceedings of the $13^{\text {th }}$ International Congress, Chania, 2013

[51] I. Matiatos, A. Alexopoulos, A. Godelitsas, Multivariate statistical analysis of the hydrogeochemical and isotopic composition of the groundwater resources in northeastern Peloponnesus (Greece), Sci. Total Environ. 476 (2014) 577-590.

[52] E. Dimitriou, P. Tsintza, Hydrogeologic investigations in Western Crete by using isotopic analyses and GIS techniques, J. Water Resour. Protect. 7 (2015) 923937.

[53] M. Katsuyama, T. Yoshioka, E. Konohira, Spatial distribution of oxygen-18 and deuterium in stream waters across the Japanese archipelago, Hydrol. Earth System. Sci. 19 (2015) 1577-1588

[54] J. Davis, Statistics and data analysis in geology, 2nd Edn., John Willey and Sons, New York, 1986, p.676. 